(Aus der medizinischen Universitätsklinik Basel [Dir.: Prof. Dr. R. Stähelin].)

\title{
Das Verhalten des Herzens bei experimentellen Anämien.
}

\author{
Von \\ Dr. med. P. Wolfer, \\ ehem. Asssstent der Klinik, Spezialarzt für innere Krankheiten in Zürich. \\ Mit 12 Textfiguren.
}

(Eingegangen am 6. Februar 1915.)

Die Frage nach der Reservekraft des Herzens, sowie nach der pathologisch-anatomischen Grundlage der Herzschwäche ist noch nicht restlos gelöst. Da diese Frage das größte Interesse des Klinikers, der die Funktionsfähigkeit und Kraft eines unter pathologischen Bedingungen stehenden Herzens eruieren möchte, beansprucht, ist sie von klinischer, experimenteller und pathologisch-anatomischer Seite des öfteren in Angriff genommen worden. Trotzdem sind die Ansichten noch nicht geklärt. Namentlich ist das funktionelle Verhalten des Herzens bei Affektionen des Gesamtorganismus, die nicht speziell die Aufmerksamkeit auf dasselbe lenken, weniger bekannt. Genauer erforscht sind die pathologisch-anatomischen Veränderungen.

Einleitend gebe ich ein kurzes Resumé der experimentellen Arbeiten. Diese ergeben:

Die Reservekraft des hypertrophischen Herzens ist im wesentlichen gleich wie die des normalen, frische Klappenfehler zeigen verminderte Reservekraft (Romberg und Hasenfeld, Wolfer). - Hunger vermindert die Herzkraft, hauptsächlich die des hypertrophischen (Eppinger und Knaffl). - Fettherztiere (Phosphor) zeigen keine Reduktion der Reservekraft - mit Ausnahme hochgradiger Vergiftungen - (Hasenfeld und Fenyvessy, Roth berger). - Das hypertrophische Herz neigt leichter zu Fettdegeneration, aber nur schwerste Verfettung führt zu Herzschädigung (Ha se nfeld). Dem Nervenmechanismus (Vagus) kommt bei Dekompensationen eine gewisse Rolle zu (Bálint). - Infektionen schädigen in erster Linie die Vasomotoren und die Gefäße (Romberg).

Diese experimentellen Feststellungen haben eine eingehende Kritik erfahren und ist des öftern diskutiert worden, ob die Befunde der experimentellen Pathologie ohne weiteres auf den Menschen übertragbar sind. Klinisch stehen sich die Anschauungen von Krehl - R o m berg (gleiche Reservekraft des hypertrophischen und des normalen Herzens) 
und Marti us (verminderte Reservekraft) gegenüber. Im allgemeinen wird doch von den meisten Autoren dem hypertrophischen Herzen eine schlechtere Prognose gestellt (Gerhardt, Eichhorst, Strümpell, Krehl, Romberg, Moritz). Besonders Gerhardt macht darauf aufmerksam, daß das hypertrophische Herz eine:gesteigerte Reservekraft haben müßte, die ihm doch zukommen sollte, da an ein solches Herz (Klappenfehlerherz) Körperarbeit und -anstrengung wesentlich höhere Anforderungen stelle. (Vgl. auch die aus den Rombergschen Zahlen deduzierten Schlüsse von Edens, der die Reservekraft des hypertrophischen Herzens kleiner berechnet als die des normalen, die Ausdauer größer und die Leistungsfähigkeit geringer.)

Die Hauptmomente zur Beurteilung des Insuffizienzherzens (Klappenfehlerherzen und andere) wurden nun auf die Beschaffenheit der muskulären Elemente verlegt und versucht, aus deren Veränderung retrograd die Insuffizienz zu erschließen. Diese Feststellungen knüpfen sich an die Arbeiten von Krehl, Romberg, Kelle, Stadler, Dehio, Letulle u. a.; es sind dies die Veränderungen des Myokards, die sich bei Myokarditis, Endokarditis, Infektionen, idiopathischen Herzhypertrophien, bei Dilatationen und bei Adipositas ergeben.

Als anatomisch wichtige Ursachen der Herzinsuffizienz kommen in erster Linie die Parenchymdegenerationen in Betracht (hyaline, körnige, fettige, Pigmentation, Vakuolen), welche nach ihrer Intensität und Lokalisation zu bewerten sind, sie werden bei den verschiedensten Affektionen gefunden. Häufig wurden Kernveränderungen gefunden, Anomalien der Form und der Färbbarkeit (Albrecht, La nge, I nada), ihre Bedeutung ist teilweise noch fraglich und berührt andere Probleme. Ferner kommen die zu Untergang der Muskelfasern und zu Schwielenbildung führenden Prozesse in Betracht, seien sie auf entzündlicher, sklerotischer oder thrombotischer Grundlage entstanden, sowie interstitielle Veränderung und solche des Seniums und der Ernährung. Die Fragmentatio cordis ist selten und inkonstant (K a rcher, Strec keise n).

Trotz allen diesen Arbeiten ist eine volle Sicherheit der funktionellen Herzdiagnostik nicht erreicht, und nicht sämtliche Unbekannten aus der Gleichung, die die Herzinsuffizienz bildet, eliminiert. In vielen Fällen ist ein Rekurrieren auf funktionelle Erschöpfung und Erlahmung notwendig (Gerhardt, Romberg, Krehl, Ka ufmann, Martius, v. Schrötter [Kongreß 1899]). Der Standpunkt, den abschließend 1914 Moritz einnimmt, diene zur Illustration: „In der Schlußfolgerung, daß die pathologische Anatomie mindestens für einen Teil der Fälle von Herzerlahmung die Erklärung schuldig bleibe, kommen fast alle neuen Autoren überein, nur über die Zahl der unbefriedigenden Antworten gehen die Ansichten auseinander" (KrehlMarchand). 
Diese Fälle, die einer pathologisch-anatomischen Grundlage entbehren, zwingen uns, auf Hypothesen zu rekurrieren und führen dazu, das Herz nicht als einziges losgelöstes Organ zu betrachten, sondern komplexe Faktoren (Alter, Ernährung, Konstitution, Zustand der Gefäße, mechanische Kreislaufsveränderungen, Contractilität, nervöse Einflüsse) in Berücksichtigung zu ziehen und den Unterschied von Herzen mit a priori vermindertem mechanischem Koeffizienten anzunehmen.

Von besonderer Bedeutung für meine Versuche sind das sog. „Fettherz" und das Herz bei Anämie, auf welche zwei Punkte ich deshalb noch gesondert eingehe. - Die experimentellen Befunde ergeben keine besondere Schädigung des Fettherzens, schon Welch (1888) fand normales Verhalten. Die chemische Analyse (Krehl) ergab keinen Zusammenhang zwischen Stärke des Fettgehaltes und Schwäche des Herzens, und ein Zusammenhang, der aus dem Vorhandensein von Fett (quantitativ) eine Herzinsuffizienz erschließen läßt, besteht nicht (Krehl, Romberg, Moritz). Durch Leyden sind die verschiedenen Formen des „Fettherzens“ gesondert und ihre Zusammengehörigkeit mit der Adipositas universalis und mit anderen Herz- und Gefäßkrankheiten klargelegt worden. Ebenfalls noch nicht gelöst ist die Frage der autochthonen Entstehung des Fettes (Leick und Winkler), eine Frage, die die Verfettung auf die Unmöglichkeit der Muskelfibrillen zugeführtes Fett zu verarbeiten, hinschiebt, Ebenfalls verschieden äußern sich die Autoren über die klinische Bedeutung der Verfettung, für dieselbe haben sich ausgesprochen: Friedreich, Eichhorst, Rosenstein, Schrötter, zweifelnd äußern sich: Duschek, Strümpell, Fräntzel (Moritz). Daß natürlich hochgradige Fettmetamorphose durch Zerstörung der Muskelfasern und Ersatz derselben durch nicht contractiles Material, sowie durch Beengung und Ballast schädigt, ist ohne weiteres anzunehmen. Als Krankheit sui generis darf seit Romberg, Leyden usw. das „Fettherz" nicht mehr aufrechterhalten werden, da es sich doch meistens als Degenerationserscheinung bei anderen Herzaffektionen findet oder als Herzbeschwerden bei Fettleibigen seine Erklärung findet, zudem ist es als solches der direkten Diagnose nicht zugänglich.

Zum Schlusse wende ich mich noch den Herzstörungen bei der Anämie zu. Als Herzveränderungen bei Anämien finden wir Dilatationen angegeben, welche infolge häufiger Retraktion der Lungenränder und Hochstand des Zwerchfells verschieden und vorsichtig $\mathrm{zu}$ beurteilen sind. Der Blutdruck ist normal oder herabgesetzt, der Puls meist weich und beschleunigt. Ga utier beschreibt in einigen Fällen Hypertrophie des Herzens bei Chlorose, bedingt durch Abnahme der funktionellen Leistungsfähigkeit des Herzmuskels, die normale Zirkulation bedeute für einen solchen Muskel erhöhte Arbeitsleistung, und deshalb 
wird das Herz zur Hypertrophie und Dilatation geführt. Le ube äußert sich skeptisch gegenüber einer Herzhypertrophie bei Anämie. Häufig findet man bei Anämischen akzidentelle Herz- und Gefäßgeräusche, welche auf verschiedene Weise erklärt werden (funktionell, muskuläre Insuffizienz, veränderte Wandspannung, geringer Aortendruck). Des ferneren ist bei Anämie das Spiel der Vasomotoren ein wechselndes. Daß bei Kachexien und Anämien eine Verschlechterung der Herzernährung vorhanden ist, liegt in der Natur der Affektion. Mohr fand das Schlagvolumen des Herzens gesteigert, und zwar beträgt die Steigerung etwa $20-30 \%$, durch welchen ,,teleologischen Vorgang“" der O-Mangel des anämischen Blutes bis zu einem gewissen Grade ausgeglichen wird. Nach Lazarus kommt bei posthämorrhagischer Anämie keine Verminderung der Blutmenge vor (ausgenommen bei hochgradigen Blutungen), bei Perniciosa ist sie meist stark herabgesetzt.

Ưber die pathologische Anatomie des Anämieherzens ist wenig bekannt, da kaum Anämien außer der Perniciosa zur Sektion kommen. Als wichtigster Befund ist bei ihr die fettige Degeneration der Organe, welche mehr oder weniger ausgedehnt sein kann, beschrieben, doch kann diese Veränderung am Herzen auch fehlen (Nägeli). Kraus gibt eine Zusammenstellung dieser Veränderungen, er fand bei 24 eigenen autoptisch gesicherten Fällen von perniziöser Anämie 22 mal Fettdegeneration, von 62 Fällen der Literatur waren alle mit Ausnahme von 5 verfettet. Über Herzveränderung bei Perniciosa gibt Kraus noch folgende interessante Zusammenstellung: I. von 47 eigenen Fällen $30 \mathrm{mal}$ Herzdämpfung vergrößert, $7 \mathrm{mal}$ Dilatation, $42 \mathrm{mal}$ systolische und $8 \mathrm{mal}$ diastolische Geräusche an der Spitze; II. von 82 Fällen der Literatur 29 mal mehr oder weniger Dilatation, 32 mal Herzdämpfung vergrößert. In den Fällen von Herzvergrößerung fand Kraus durch Perkussion und Röntgenuntersuchung eine Dilatation nach rechts und links, im Verlauf der Krankheit erweitert sich das Herz progressiv. Nach Lazarus ist die Fettdegeneration des Myokards fast in jedem Falle vorhanden, am stärksten ist sie in den Papillarmuskeln des linken Herzens, dann in denen des rechtèn, dann in Muskulatur des linken und rechten Ventrikels und in den Vorhöfen ausgesprochen. In vereinzelten Fällen wurde Verfettung vermißt (Litten, Müller, Stricker, Quincke, Laache). Das Herz im ganzen ist von normaler Größe oder etwas kleiner gefunden worden, zuweilen der rechte Ventrikel geringgradig erweitert. Geringe Hypertrophie beider Kammerwände erwähnt Eichhorst bei normalen Klappen.

Die Ursachen der Herzinsuffizienz sind also nicht immer und nicht nur in anatomischen Veränderungen zu suchen, sondern Vorgänge des pathologisch-physiologischen Geschehens sind zu berücksichtigen.

Nach diesen Erörterungen gehe ich zu meinen experimentellen 
Untersuchungen über. Ich stellte mir die Aufgabe, in einer größeren Versuchsreihe die Herzverhältnisse (funktionell und anatomisch) bei verschiedenen Graden und Arten von experimentellen Anämien zu prüfen. Ich war auf wenig bearbeitetem Gebiet, das erweist die Notiz von Krehl: „Auch chronisch allgemeine Anämien schädigen zweifellos oft das Herz, doch ist der Grund dafür noch nicht sicher bekannt, man muß sowohl an eine mangelhafte Ernährung des Muskels als auch an Degenerationen der Fasern denken." (Pathol. Physiol., S. 59.) Die Fragen, deren Beantwortung ich anstrebte, waren die: „1. Wie verhält sich das Herz bei experimentellen Anämien? 2. Lassen sich bestimmte pathologisch-anatomische Veränderungen eruieren, welche mit der Herzkraft in Beziehung stehen? 3. Welche Gewichtsverhält nisse finden wir bei anämischen Zuständen?"

Die Anämien wurden durch Entbluten, Injektion von salzsaurem Phenylhydrazin, Anilin, sowie durch Kombination dieser Methoden hervorgerufen und unterhalten. Weitere Beobachtungen wurden nicht gemacht. Ich beschränkte mich auf die systematische Feststellung des Hämoglobingehaltes und der Erythrocytenzahl, dieser wurde mit dem Hämometer nach Sahli, dessen. Normalgehalt bei $80 \%$ liegt, bestimmt und jene in der Türkschen Zählkammer. Der normale Hämoglobingehalt bei Kaninchen schwankt zwischen 50-70\%, die Erythrocyten um 4-5 Millionen.

Bei diesen anämischen Tieren nahm ich die Prüfung der Herzkraft nach schon publizierter Methode vor (Archiv f. experim. Pathol. u. Pharmakol. 68). Die Technik war kurz folgende: Rechte Carotis wird mit Einschaltung eines Hürthleschen Gummimanometers mit dem Kymographion verbunden (Flüssigkeit: Magn. sulf. 20\%). Präparation des Arcus aortae und Ligatur desselben nach Abgang der Carot. sinistra unter Kontrolle des Blutdruckes. In kurzen Intervallen von je 5 Minuten wurde der Blutdruck aufgezeichnet. Während des Versuchs ständig Äthernarkose und künstliche Atmung. Versuchsdauer: 3 Stunden.

Von andern Autoren (Romberg und Hasenfeld) werden noch andere Methoden zur Prüfung der Reaktionsfähigkeit des Herzens angewandt, ich verwendete nur die Aortenunterbindung, die ich als stärkstes Kreislaufhindernis erachte. Die Herzwägung wurde nach der von mir (l. c.) modifizierten Methode vorgenommen.

Meine Untersuchung gliedert sich entsprechend der Art der Anämisierung in folgende Gruppen, von denen jede 10 Versuche umfaßt:

1. Normalversuche,

2. Anilinanämien,

3. Phenylhydrazinanämien,

4. Entblutungsanämien,

5. Kombinierte Anämien. 


\section{Gruppe I.}

(Vgl. Fig. 1 und 2.)

Diese Gruppe umfaßt die Kontrollen bei normalen Tieren, ${ }^{5}$ diese Versuche wurden von mir schon früher mit genau derselben Technik

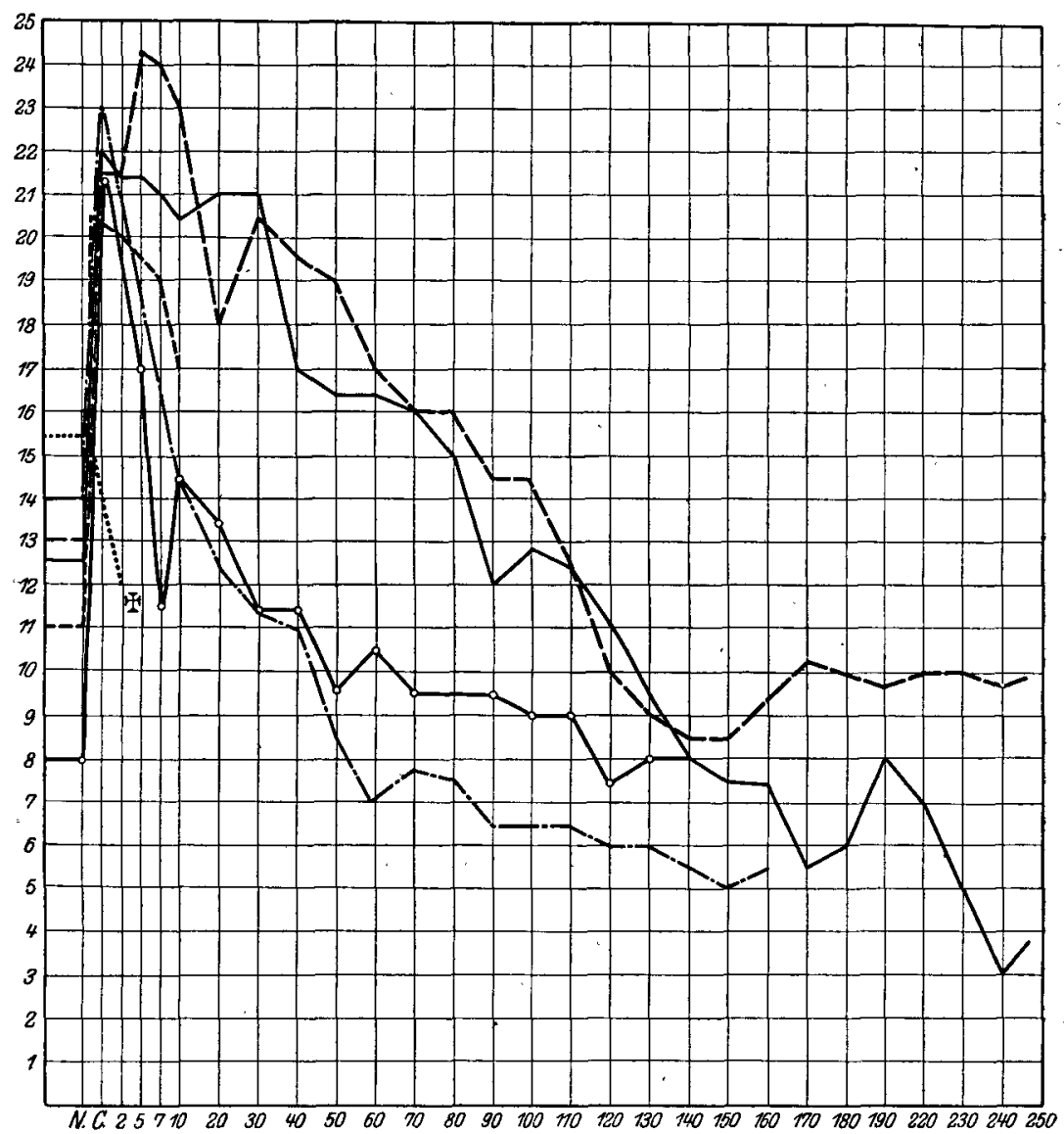

Fig. ${ }^{1}$ ). Normalversuche.

ausgeführt (l. c.); ich konnte sie deshalb ohne weiteres als Vergleichsmaterial für diese pathologischen Gruppen verwenden. Ich zitiere nur

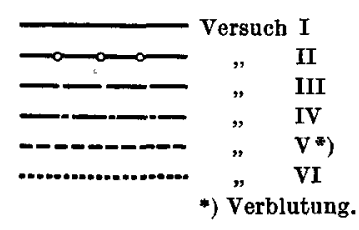

1) Sämtliche Kurven wurden in derselben Weise gewonnen, die Drucksteigerung absolut ohne Umrechnung in $\mathrm{H}_{2} \mathrm{O}$ oder Quecksilber von der Normalstellung aus berechnet. Reduziert wurden sie auf ein Zeitintervall von 10 Minuten. $\mathrm{N}=$ Ausgangsstellung. 


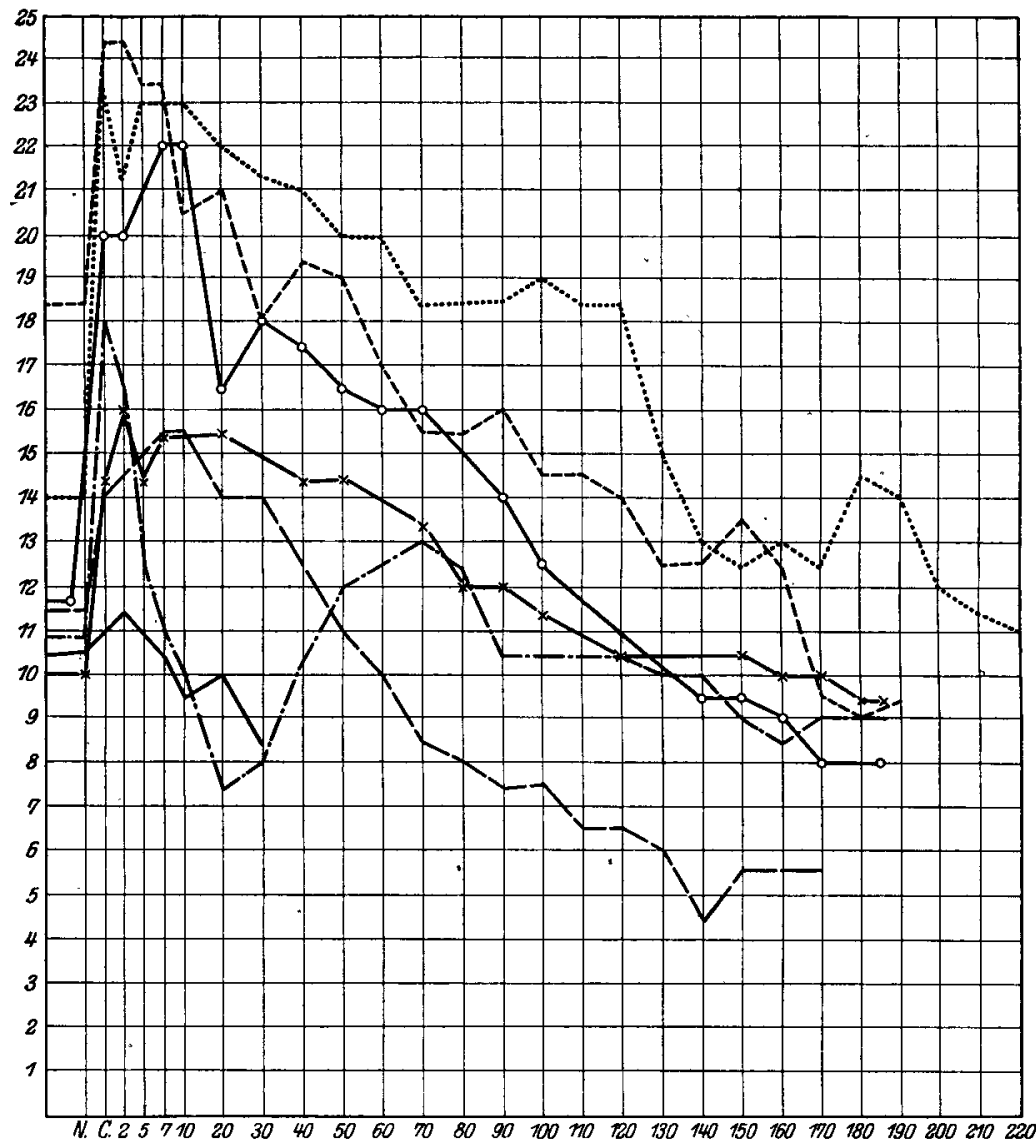

Fig. 2. Normalversuche.

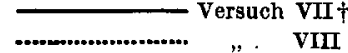

fragen auf meine frühere Arbeit.

In bezug auf zeitlichen Ablauf zeigte sich:

1. daß das normale Herz trotz stärkster

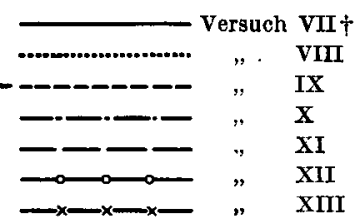
Inanspruchnahme befähigt ist, stunden-

lang weiter zu arbeiten und eine analysierbare Kurve zu liefern;

2. daß die diese Mehrbelastung nicht ertragenden Herzen einen kleinen Teil ausmachen (2 von 12);

3. daß es normale Herzen gibt, die kurze Zeit nach dieser Mehrbelastung des Kreislaufs ihre Tätigkeit einstellen.

Als Mittelwerte für die Drucksteigerung nach der Kompression ergaben sich 6,219 mm für die Systole, 1,56 für die Diastole (Fußpunkt), 4,73 mm für die Amplitude. 
1. Sämtliche Versuche (mit 2 Ausnahmen) reagierten mit intensiver Drucksteigerung auf die Aortenkompression.

2. Eine Gesetzmäßigkeit in betreff Rückkehr zur normalen Druckhöhe oder in bezug auf den zeitlichen Abląuf konnte nicht gefunden werden.

3. Im Lauf des Versuches stellt sich der Druck auf niedere Werte ein und kann lange und regelmäßig so bestehen.

4. Sämtliche Kurven waren bei 180 Minuten oder bei ihrem Abbruch sehr deutlich, regelmäßig und schön, nur zwei Versuche gingen in sehr kurzer Zeit zu Ende.

5. Druckmaxima meist gleich oder kurz nach der Kompression erreicht.

\section{Gruppe II.}

(Vgl. Fig. 3 u. 4 und Tabelle XVI auf S. 339.)

Die beiden ersten pathologischen Gruppen umfassen Versuche mit den der Reihe des Antipyrins angehörenden Stoffen Anilin und salzsaurem Phenylhydrazin.

Anilin gehört zu den Blutgiften, welche Hämoglobin in Methämoglobin umwandeln, außerdem kommt es dabei zu Hämolyse, also zu direkter Zerstörung der Erythrocyten (Nägeli); nach Heinz beginnt die Methämoglobinbildung zuerst, die Veränderungen der Erythrocyten treten erst nach einer bestimmten Zeit auf; ferner wirkt Anilin nur bei chronischer Vergiftung.

Klinisch führt Nitrobenzolvergiftung zu Eingenommensein des Kopfes, Cyanose, Beängstigung, Atemnot, Bewußtseinstörung, Sopor.

Auch eine Anilinkachexie ist beschrieben (Kobert). Von Kobert und Friedstein wird die neurotoxische Komponente der Vergiftung - Reizung und Lähmung - betont. In betreff Detailfragen verweise ich auch für die andern Gruppen auf die Handbücher (Heinz, Kobert, Nägeli).

Nach Massini können am Herzen und an den Gefäßen bei Nitrobenzolvergiftungen Störungen auftreten, sie bestehen in akuter Herzdilatation, Galopprhythmus und Blutdrucksenkung. Nach demselben Autor treten Anämien auf, bei welchen, wie im Tierexperiment, das Auftreten des embryonalen Bluttypus beobachtet werden konnte. Galopprhythmus konnte Massini auch in einem Fall von Anilinvergiftung nachweisen, der, da er leicht war, zu keinen abnormen Veränderungen des Blutbildes führte und der auch keine Abnormität des Orthodiagramms aufwies.

Zur Anämisierung verwandte ich Anilinöl subcutan. Als Anämisierungsbeispiele führe ich folgende zwei Versuche an, die Resultate der andern sind gekürzt wiedergegeben (Tab. I). 
Tabelle I.

Versuch I.

\begin{tabular}{|c|c|c|c|c|}
\hline 1980 & 3. XII. & $50 \%$ & 4360000 & \\
\hline & 5. XII. & $50 \%$ & 4224000 & \\
\hline & 7. XII. & $45 \%$ & 3960000 & \\
\hline & 10. XII. & $47 \%$ & 4472000 & \\
\hline & 11. ХПT. & & & 0,3 Anilinöl \\
\hline & 12. XII. & $47 \%$ & 4080000 & $0,3 \quad$, \\
\hline & 13. XII. & $38 \%$ & 3912000 & 0,3 \\
\hline & 14. XII. & $33 \%$ & 3712000 & 0,3 \\
\hline & 15. XII. & & & 0,3 \\
\hline & 16. XII. & $20 \%$ & & 0,3 \\
\hline 1770 & 17. XII. & $\mid 14 \%$ & 2176000 & \\
\hline
\end{tabular}

Versuch X.

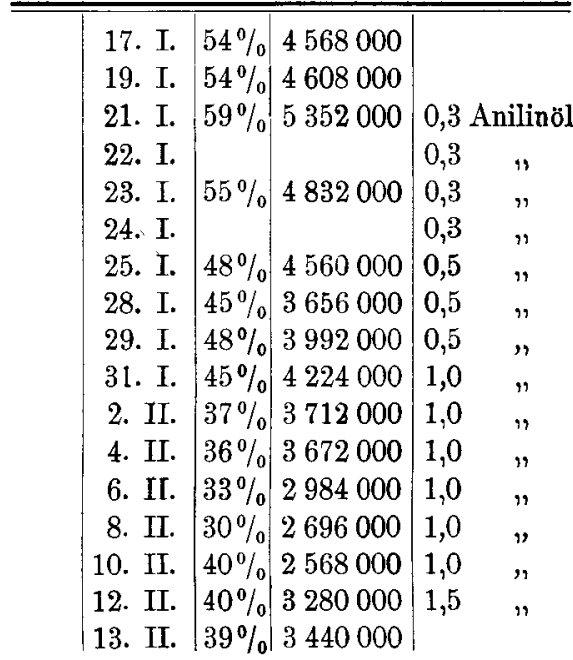

Pause

Die Versuche zeigen, daß durch fortgesetzte Anilininjektionen chronische Vergiftung — eine Anämie erzeugt werden kann, doch erfordert die Ausbildung derselben eine gewisse Zeit und die ersten Injektionen führen meist zu keiner wesentlichen Anämie. Interessant ist Versuch $\mathrm{X}$, dort wurde in der ersten Periode eine Anämie nicht erreicht, der Versuch deshalb abgebrochen und 3 Monate später — nach völliger Restitution des Blutbildes - mit positivem Resultat wiederholt. Die Dosierung wurde verschieden gewählt, zur Erzielung eines Effektes waren 0,5-1,0 p. D. notwendig, mit entsprechender Vorsicht bei tiefen Werten. Die Tatsache, daß das Anilin jedenfalls nicht nur auf das Blut, sondern auch auf das Nervensystem wirkt, machte die Steigerung der Anämien unter 20\% schwierig, da in diesen Tiefen häufig geringe Dosen schlecht ertragen wurden und Exitus bei Reininjektion erfolgte. Wurde nicht behandelt, erholten sich die Tiere sehr rasch, deshalb mußten die mit einem Hämoglobingehalt von etwa 
$20 \%$ ausgewählt werden. Tabelle II gibt Auskunft über den Grad und die Dauer der Anämie.

Tabelle II.

\begin{tabular}{|c|c|c|c|c|c|}
\hline & $\begin{array}{l}\text { Gewichts- } \\
\text { abnahme }\end{array}$ & $\begin{array}{l}\text { Dauer der } \\
\text { Anämie }\end{array}$ & $\begin{array}{c}\text { Grad der } \\
\text { Anämie }\end{array}$ & Hypertrophie & Versuchsdauer \\
\hline I. & 210 & 4 Tage & $14 \%$ & + & $175^{\prime} \dagger$ \\
\hline II. & 200 & $5 \quad$, & $26 \%$ & & $180^{\prime} \dagger$ \\
\hline III. & 210 & $12 "$ & $25 \%$ & & $165^{\prime} \dagger$ \\
\hline IV. & 250 & $21 "$ & $20 \%$ & & $150^{\prime}+$ \\
\hline V. & 510 & 5 & $14 \%$ & & $145^{\prime} \dagger$ \\
\hline VI & 300 & 8 & $22 \%$ & & $115^{\prime}+$ \\
\hline VII. & +70 & 13 & $23 \%$ & & hält ans \\
\hline VIII. & 350 & 28 & unter $10 \%$ & & $170^{\prime} \dagger$ \\
\hline IX. & +100 & $7 \quad$ & $19 \%$ & & $145^{\prime} \dagger$ \\
\hline $\mathrm{X}$ & 390 & $2 \mathrm{mal}$ im Vers & $18 \%$ & & hält aus \\
\hline
\end{tabular}

Bei diesen Anämietieren wurde der Herzversuch vorgenommen. In einem Fall $\mathrm{V}$ wurde die linke Carotis zur Registrierung verwendet (Gewichtsverhältnisse vgl. Tab. XVI).

Ich lasse die nach der Kompression eintretenden Drucksteigerungen (um Millimeter absolut) in Tabelle III folgen:

Tabelle III.

\begin{tabular}{r|c|c|c}
\hline \hline & $\begin{array}{c}\text { Systolisch } \\
\text { Höhe Gipfelpunktes }\end{array}$ & $\begin{array}{c}\text { Diastolisch } \\
\text { Höhe des Fußpunktes }\end{array}$ & Amplitude \\
\hline \hline I. & 10 & 6 & 4 \\
II. & 5,5 & 2,5 & 3 \\
III. & 8,5 & 7,5 & 1 \\
IV. & 8 & 7 & 1 \\
V. & 10,5 & 12 & $-1,5$ \\
VI. & 7 & 5 & 2 \\
VII. & 5,5 & 3,5 & 2 \\
VIII. & 4 & 1 & 3 \\
IX. & 4,5 & 6,5 & -2 \\
X. & 9 & 5,5 & 3,5 \\
\hline Mittelwert . & 7,25 & 5,65 & 1,6 \\
Normal . . & 6,2 & 1,56 & 4,73
\end{tabular}

In deutlicher Weise zeigt diese Reihe in bezug auf die Normalen, daß die systolische Kraft keineswegs geringer ist, im Gegenteil läßt das Gros der Versuche eine Steigerung des systolischen Höhepunktes erkennen und auch der Mittelwert übersteigt den des Normalen. Im Gegensatz dazu steht die diastolische Erhebung, die im Einzelversuch 


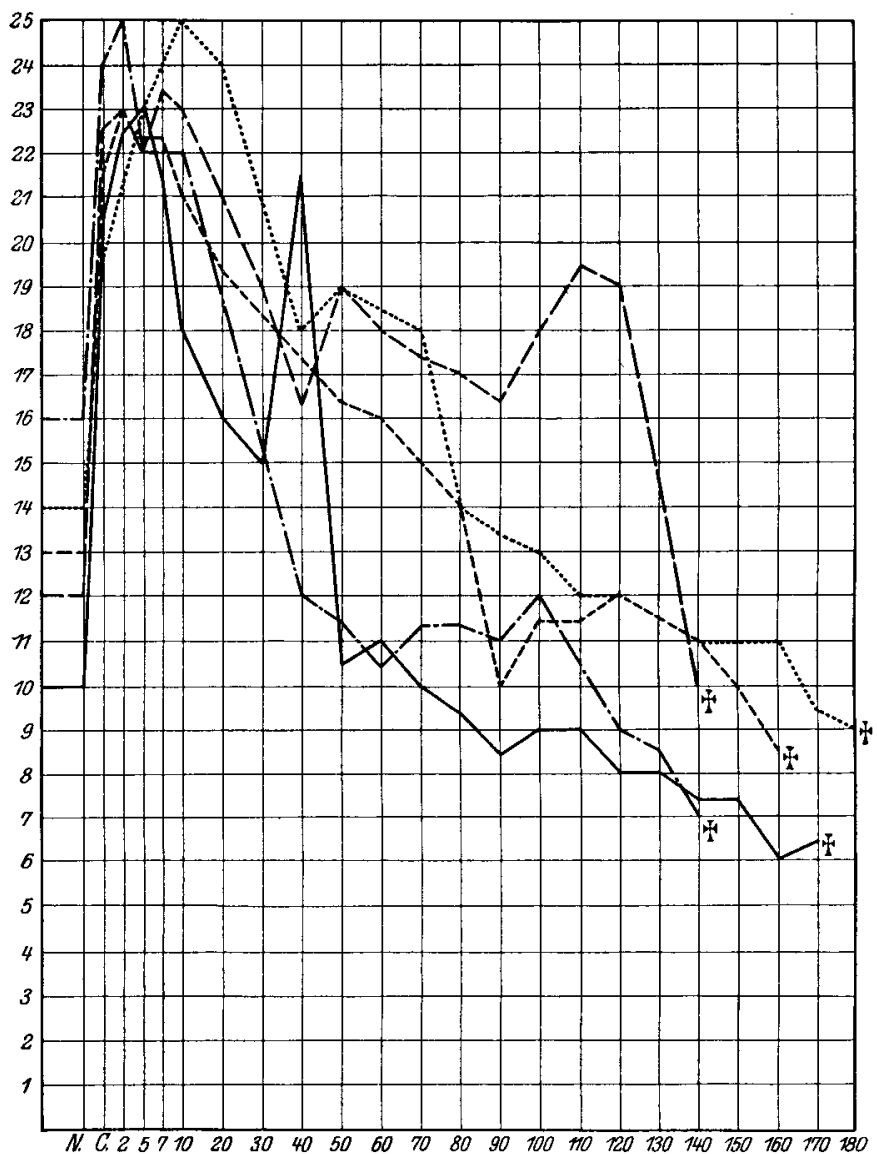

Fig. 3. Anilin. - Versuch $\mathrm{I} \dagger$ wie im ganzen den Normalwert übersteigt,
wir sehen sogar das eigentümliche Verhalten,
daß der diastolische Anstieg den systolischen überragt (V. und IX.). Konform mit diesem Verhalten ist die Amplitude, die weit hinter dem Anstieg der Normalen zurückbleibt, sich nur in geringem Grade vergrößert und in 2 Fällen sogar verkleinert. Diese von den Normalversuchen und auch von Versuchen bei Herzhypertrophien verschiedenen Ergebnisse werden später zu berücksichtigen sein. Im wesentlichen kommt es darauf an, die zeitlichen Verhältnisse des Druckablaufs zu beobachten. Als Illustration führe ich die Tabelle IV an, die uns nebst den maximalen Druckwerten deren Rückkehr zu den Ausgangswerten und deren Verhalten nach dreistündiger Kompression zeigt: 
Tabelle IV.

\begin{tabular}{|c|c|c|c|c|c|c|c|}
\hline & \multicolumn{4}{|c|}{ Höchster Druck } & \multirow{2}{*}{\multicolumn{2}{|c|}{$\begin{array}{l}\text { Ausgangsdruck } \\
\text { erreicht nach } \\
\text { Minuten }\end{array}$}} & \multirow{3}{*}{$\begin{array}{l}\text { Verhalten bei } \\
180 \text { Minuten }\end{array}$} \\
\hline & \multirow{2}{*}{\multicolumn{2}{|c|}{\begin{tabular}{c|c}
\multicolumn{2}{c}{ systolischer } \\
Maximum & Maximum \\
nach & beträgt \\
Minuten & mm
\end{tabular}}} & \multicolumn{2}{|c|}{ diastolischer } & & & \\
\hline & & & \begin{tabular}{|} 
Maximum \\
nach \\
Minuten
\end{tabular} & $\begin{array}{c}\text { Maximum } \\
\text { beträgt } \\
\text { mm }\end{array}$ & systol. & $\begin{array}{c}i \\
\text { diastol. }\end{array}$ & \\
\hline I. & 5 & 23 & 7 & 17 & 70 & 85 & $175^{\prime} \dagger$ \\
\hline II. & 10 & 25 & 10 & 18 & 80 & 80 & $\begin{array}{c}\dagger, \text { Kurve schwach, } \\
\text { große Pausen, } \\
\text { lange Wellen }\end{array}$ \\
\hline III. & 2 & 23 & 2 & 19,5 & 80 & 85 & $165^{\prime}+$ \\
\hline IV. & 2 & 25 & 2 & 17 & 30 & 40 & $150^{\prime} \dagger$ \\
\hline $\mathrm{V}$. & 7 & 23,5 & 5 & 17 & 140 & 140 & $145^{\prime} \dagger$ \\
\hline VI. & sofort & 22,5 & sofort & 18,5 & 20 & 15 & $115^{\prime} \dagger$ \\
\hline VII. & sofort & 21 & sofort & 15,5 & 25 & 20 & schöne Kurve \\
\hline VIII. & 55 & 22 & 55 & 12,5 & 170 & 150 & $170^{\prime}+$ \\
\hline IX. & 7 & 26 & 10 & 20,5 & 110 & 125 & $145^{\prime} \dagger$ \\
\hline $\mathrm{X}$. & 2 & 26 & 2 & 13,5 & 25 & 160 & Kurve regelmäßig \\
\hline ittel & & 23,7 & & 16,9 & & & \\
\hline Normal & & 19,9 & & 13,3 & & & \\
\hline
\end{tabular}

Der Ausgangsdruck zeigt gleiche Höhe wie der normale; beide sind zwischen 10-15 mm. Nach Kompression tritt in der Systolenkurve keine wesentliche Änderung ein, der Abfall ist konform und für jeden Anilinversuch kann ein entsprechender Normalversuch gefunden werden. Den systolischen Maximalwert erreichen sie etwas später, selten gleich nach der Kompression, im ganzen ist er höher als der normale, immer über $20 \mathrm{~mm}$. Ihren diastolischen Maximalwert erreichen sie meistens nach der Kompression und er ist ebenfalls höher als der normale. Die Rückkehr zu den Ausgangswerten zeigt, mit Ausnahme einer Verzögerung der diastolischen Werte, keinen Unterschied.

Andere Punkte ergeben sich im zeitlichen Ablauf. Zwei der Normalversuche kamen rasch ad finem, die andern ertrugen die Kompression bis $180^{\prime}$. Sämtliche Anilinversuche konnten bis $100^{\prime}$ ausgedehnt werden, dann aber zeigte sich, daß bis $180^{\prime} 8$ Anilintiere unter Fallen des systolischen Druckes ad exitum kamen. In einem Fall (II) war aus der schwachen, langsamen und irregulären Kurve zu erschließen, daß das Herz an der Grenze seiner Leistungsfähigkeit angekommen war.

Das Resumé ergibt:

1. Ziemlich normale Ausgangspunkte.

2. Etwas gesteigerte systolische Maximalerhebung.

3. Stärkeren Anstieg des Fußpunktes, geringeren der Amplitude. 


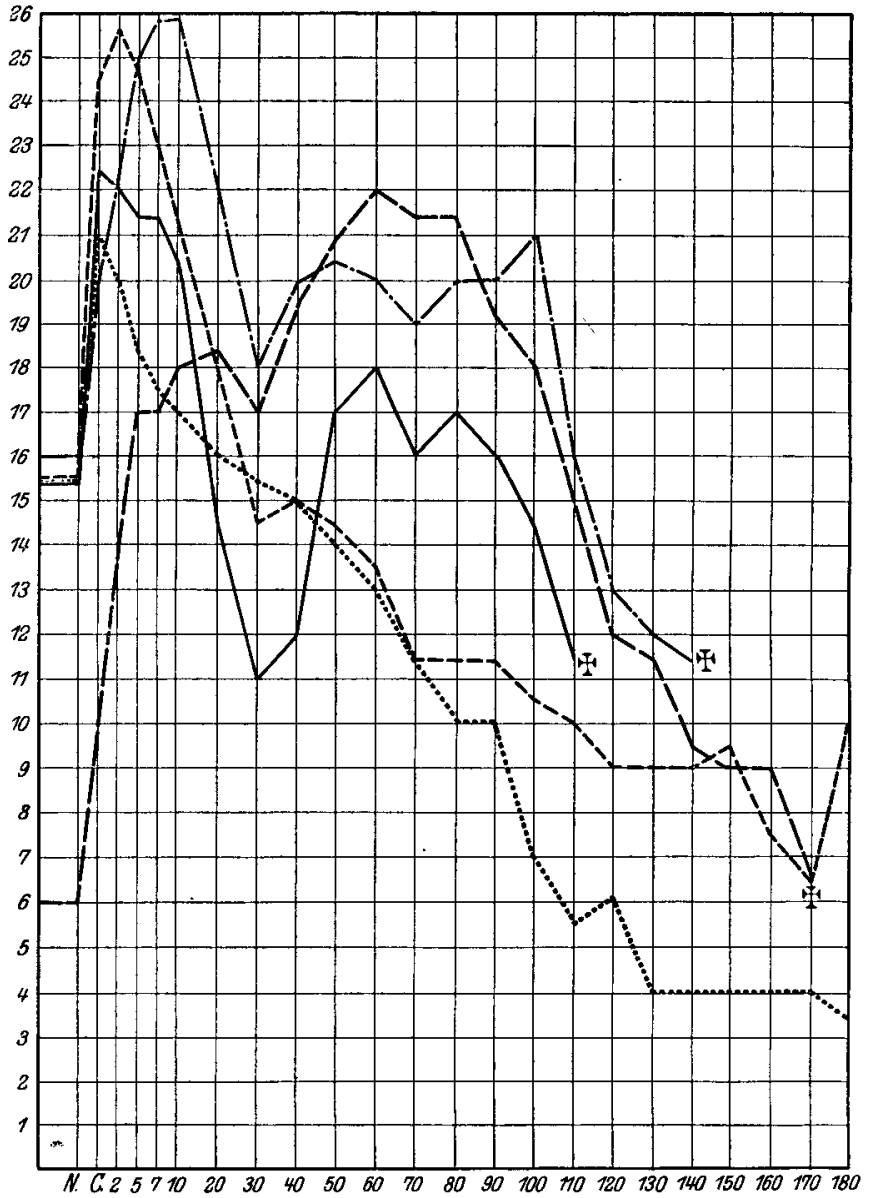

Fig. 4. Anilin.

4. Normale Rückkehr zu den Ausgangswerten.

5. In keinem Fall raschen Exitus, in

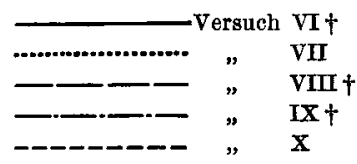
8 Fällen Exitus zwischen 100 bis 180 Min.

6. Maximaldruck selten gleich nach der Kompression erreicht.

Die Kurvenbilder zeigen:

I. Bei $2^{\prime}$ und $5^{\prime}$ arhythmisch, dann regelmäßig, bei $145^{\prime}$ Alternans der unter zunehmender Schwäche verschwindet.

II. Nach Kompression Andeutung von Bigemini. 2', 2' $7^{\prime}$ bigeminusähnliche dikrote Welle, von $160^{\prime}$ an länger werdende Pausen, Druckabfall. 
III. Nach Kompression einzelne Extrasystolen. Bei $165^{\prime}$ Sinken und lange Pausen.

IV. Immer regelmäßig. Bei $135^{\prime}$ Alternans. Von $145^{\prime}$ an arhythmisch und Absinken.

V. Von $10^{\prime}$ an regelmäßig, nach Kompression einzelne Extrasystolen. Bei $140^{\prime}$ Absinken.

VI. Nach Kompression einzelne Extrasystolen. Bei 2' dikrot, sonst regelmäßig. Bei $140^{\prime}$, Absinken.

VII. Immer regelmäßig.

VIII. Immer regelmäßig.

IX. Immer regelmäßig.

$\mathrm{X}$. Nach Kompression einzelne Extrasystolen, sonst immer regelmäßig.

\section{Gruppe III.}

(Vgl. Fig. 5 u. 6 und Tabelle XVII auf S. 340.)

„Phenylhydrazin $\mathrm{C}_{6} \mathrm{H}_{5} \mathrm{NHNH}_{2}$ ist eines der gefährlichsten Blutgifte, es tötet schon in kleinen Dosen. Das Blutbild zeigt neben Schrumpfung der Erythrocyten Körnchenbildung derselben. Die durch Phenylhydrazin geschädigten Blutkörperchen (und zwar werden alle Blutscheiben verändert) gehen sämtlich zugrunde. Die abgestorbenen Erythrocyten werden aus dem Kreislauf entfernt; und zwar erfolgt diese Elimination sehr rasch: in 4 Tagen ist die Hauptmasse der veränderten Blutkörperchen aus dem strömenden Blut verschwunden. Die Zahl der Roten kann bis auf 1 Million im $\mathrm{cmm}$ sinken, ohne daß das Leben erlischt" (Heinz).

Ich führe ein Beispiel eines solchen Anämisierungsversuches in Tabelle V an. Die Applikation des salzsauren Phenylhydrazins erfolgte subcutan.

Tabelle V. Versuch VII.

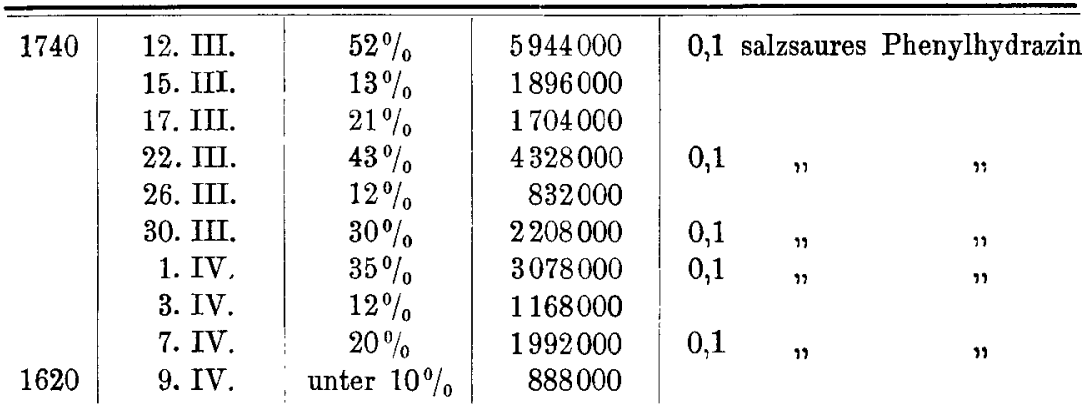

Daß eine Anämie erreicht wurde, zeigt folgende Zusammenfassung. Wie bei-der ersten Gruppe, so gehen sie auch hier mit einem Gewichts- 
verluste einher. Bemerkenswert ist ferner die von anderen Autoren schon festgestellte rasche Erholung (Itami). (Siehe Tabelle VI.)

Tabelle VI.

\begin{tabular}{|c|c|c|c|c|c|}
\hline & $\begin{array}{l}\text { Gewichts- } \\
\text { abnahme }\end{array}$ & $\begin{array}{c}\text { Dauer der } \\
\text { Anämie }\end{array}$ & $\begin{array}{c}\text { Grad der } \\
\text { Anämie }\end{array}$ & Hypertrophie & Versuchsdauer \\
\hline I. & - & 9 Tage & $34 \%$ & vorhanden & halt aus \\
\hline II. & 750 & $7 n$ & $11 \%$ & & $n \quad n$ \\
\hline III. & 1000 & $11 n$ & $25 \%$ & & \\
\hline IV. & 150 & 11 & $14 \%$ & & \\
\hline V. & 420 & 3 & kaum $10 \%$ & & $110^{\prime}+$ \\
\hline VI. & 270 & 32 & $13 \%$ & & hält aus \\
\hline VII. & 120 & 28 & unter $10 \%$ & vorhanden & $130^{\prime} \dagger$ \\
\hline VIII. & 340 & 10 & $20 \%$ & & hält aus \\
\hline IX. & 500 & 52 & $13 \%$ & & $"$ \\
\hline $\mathrm{X}$. & 850 & $54 n$ & $10 \%$ & & $125^{\prime} \dagger$ \\
\hline
\end{tabular}

Es folgen in Tabelle VII die Drucksteigerungen nach der Kompression um Millimeter.

Tabelle VII.

\begin{tabular}{r|c|c|c}
\hline \hline & $\begin{array}{c}\text { Systole: } \\
\text { Höhe des Gipfel- } \\
\text { punktes }\end{array}$ & $\begin{array}{c}\text { Diastole: } \\
\text { Höhe des Fuß- } \\
\text { punktes }\end{array}$ & Amplitude \\
\hline I. & 11 & 6,5 & 4,5 \\
II. & 7,5 & 4,5 & 3 \\
III. & 7 & 1,5 & 5,5 \\
IV. & 6 & 7 & -1 \\
V. & 9 & 9 & 0 \\
VI. & 4 & 2 & 2 \\
VII. & - & - & - \\
VIII. & 13 & 6 & 7 \\
IX. & 14 & 11 & 3 \\
X. & 4 & 6 & -2 \\
\hline Mittel & 8,4 & 6 & 2,4 \\
Normal & 6,2 & 1,56 & 4,73
\end{tabular}

Auch hier finden wir nach der Kompression gegenüber dem Normalen veränderte Werte, der Systolen- und Diastolenwert ist gesteigert, die Amplitude verkleinert. Gegenüber den Normalversuchen zeigen die Systolenkurven einen stärkeren Anstieg, teilweise ein längeres Hochbleiben und im ganzen einen bedeutend steileren Abfall der nicht hoch bleibenden Versuche. Die Detailübersicht ergibt sich aus den Kurvenbildern. 
Versuch V, ergibt nach ziemlich schöner Kurve bei $110^{\prime}$ Exitus.

Versuch VII, infolge Fehler am Apparat konnte erst von $55^{\prime}$ an eine schöne Kurve erhalten werden, bei $130^{\prime}$ erfolgte Exitus.

Versuch $\mathrm{X}$, zeigt relativ späten und nicht sehr hohen Anstieg, bei $105^{\prime}$ treten lange Herzpausen ein und unter Zunahme derselben, verbunden mit Sinken der systolischen Welle bei 125' Exitus.

Ich registriere in Tabelle VIII das Verhalten der Einzelversuche:

Tabelle VIII.

\begin{tabular}{|c|c|c|c|c|c|c|c|}
\hline & \multicolumn{4}{|c|}{ Höchster Druck } & \multirow{2}{*}{\multicolumn{2}{|c|}{$\begin{array}{l}\text { Ausgangsdruck } \\
\text { erreicht nach } \\
\text { Minuten }\end{array}$}} & \multirow{3}{*}{$\begin{array}{l}\text { Verbalten bei } \\
180 \text { Minuten }\end{array}$} \\
\hline & \multicolumn{2}{|c|}{ systolischer } & \multicolumn{2}{|c|}{ diastolischer } & & & \\
\hline & $\begin{array}{c}\text { Maximum } \\
\text { nach } \\
\text { Minuten }\end{array}$ & $\begin{array}{c}\text { Maximum } \\
\text { beträgt } \\
\mathrm{mm}\end{array}$ & $\begin{array}{c}\text { Maximum } \\
\text { nach } \\
\text { Minuten }\end{array}$ & $\begin{array}{c}\text { Maximum } \\
\text { beträgt } \\
\text { mm }\end{array}$ & systol. & diastol. & \\
\hline I. & 2 & 27 & 2 & 19,5 & 130 & 100 & $\begin{array}{l}\text { schöne Kurve, } \\
\text { Alternans }\end{array}$ \\
\hline II. & 2 & 23,5 & 5 & 17 & 45 & 45 & dentliche Kurve \\
\hline III. & 10 & 25,5 & 35 & 17 & 180 & 90 & (1) \\
\hline IV. & 20 & 17,5 & 35 & 11 & 115 & 185 & $"$ \\
\hline V. & sofort & 20,5 & C. & 17 & 90 & 75 & $110^{\prime} \dagger$ \\
\hline VI. & sofort & 24 & C. & 19 & 40 & 2 & deutliche Kurve \\
\hline VII. & - & - & - & - & - & 一 & $130^{\prime} \dagger$ \\
\hline VIII. & sofort & 25 & C. & 16 & 70 & 60 & deutliche Kurve \\
\hline IX. & sofort & 25 & 10 & 20 & 75 & 115 & $\begin{array}{l}\text { deutl. systol. Erheb. } \\
\text { sehr lange Pausen }\end{array}$ \\
\hline $\mathrm{X}$. & 2 & 23,5 & 2 & 16,5 & 55 & 55 & $125^{\prime} \dagger$ \\
\hline $\begin{array}{l}\text { Mittel } \\
\text { Normal }\end{array}$ & & $\begin{array}{l}23,9 \\
19,9\end{array}$ & & $\begin{array}{l}17 \\
13,3\end{array}$ & & & - \\
\hline
\end{tabular}

In ihren Maximalwerten sind Systole und Diastole gleichsinnig höher als die normalen, es zeigt sich so, daß die anfänglich beobachteten Unterschiede der Amplitude bei Maximalwerten sich ausgleichen.

Wie bei den andern Versuchen (Gruppe I und II) fällt das individuell verschiedene Verhalten der einzelnen Kurven auf, prinzipielle Momente, mit Ausnahme des etwas steileren Abfalls, lassen sich nicht eruieren.

Das Resumé ergibt:

1. Normale Ausgangswerte.

2. Gesteigerte systolische Maximalerhebung,

3 Stärkeren Anstieg des Fußpunktes, geringeren der Amplitude.

4. Steileren Abfall einzelner Kurven, etwa normale Rückkehr zu den Ausgangswerten.

5. In keinem Fall raschen Exitus, in 3 Fällen Exitus zwischen 100 bis $180^{\prime}$ Min., in einem Fall (IX) bei $180^{\prime}$ längere Herzpausen. 


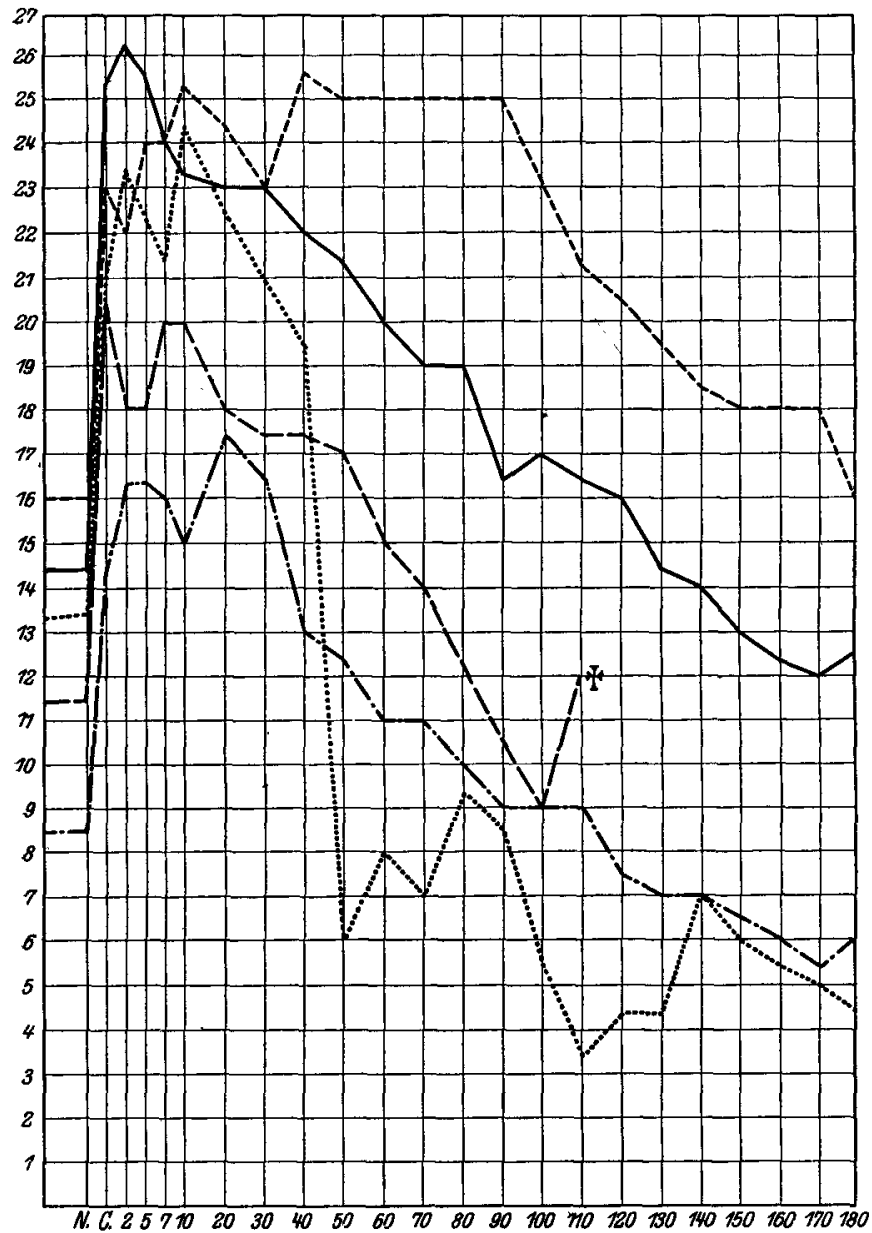

Fig. 5. Phenylhydrazin.

Als Ergänzung lasse ich den Kommentar

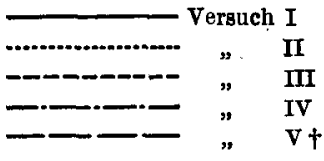
der Kurven folgen:

I. Immer regelmäßig, bei $5^{\prime}$ regelmäßige

Bigeminie, ebenfalls bei $7^{\prime}$ und $10^{\prime}$, bei $180^{\prime}$ einzelne Extrasystolen.

II. Nach Kompression dikrote Welle, ebenfalls bei $2^{\prime}$, aber regelmäßig 7-20' arhythmisch. Ziemlich häufig Extrasystolen im spätern Verlauf.

III. Dikrotie nach Kompression, 2-10' Extrasystolen. Bi- und Trigeminie, $15^{\prime}$ dikrot. Von $30^{\prime}$ an regelmäßig.

IV. Nach Kompression 2 Extrasystolen, $2^{\prime}, 5^{\prime}, 7^{\prime}, 10^{\prime}$, dikrote Welle. 


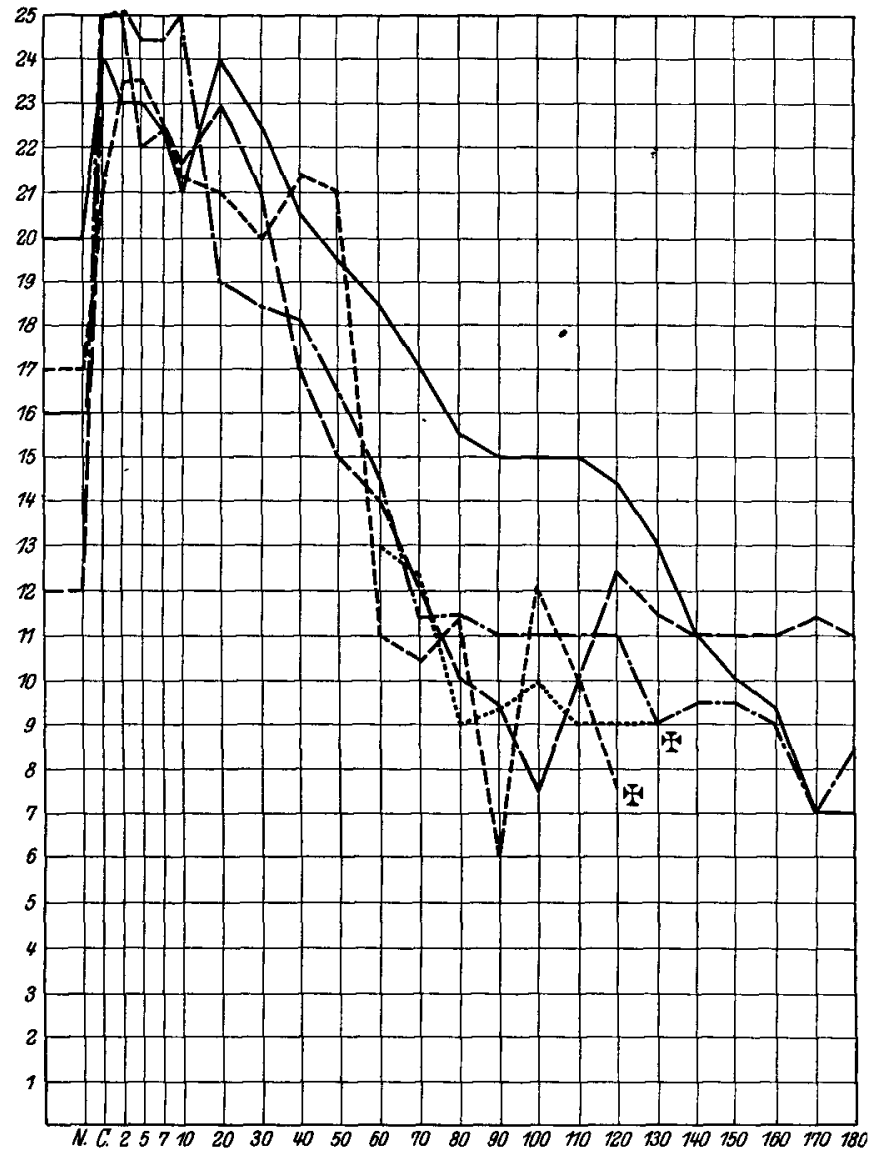

Fig. 6. Phenylhydrazin.

V. Regelmäßig von $90^{\prime}$ an inäqual.

VI. Nach Kompression bigeminusähnliche

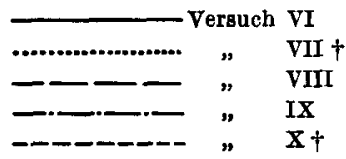
regelmäßige dikrote Welle, sonst Kurve regelmäßig.

VII. Stellenweise inäqual, sonst ohne Besonderheiten.

VIII. Bei $2^{\prime}$ Extrasystolen. 7-25' stärkere dikrote Welle, sonst ohne Besonderheiten.

IX. Nach Kompression eine Extrasystole, ebenfalls bei $2^{\prime}$ und $5^{\prime}$, sonst ohne Besonderheiten.

X. Nach Kompression seltene Extrasystole. $2^{\prime}, 5^{\prime}, 7^{\prime}$, dikrote Zacke. gegen Schluß größere Pausen. 


\section{Gruppe IV.}

(Vgl. Fig. 7 u. 8 und Tabelle XVIII auf S. 341.)

Bei dieser Gruppe wurde die einfachste Methode eine Anämie zu erzeugen, angewandt, nämlich der Blutentzug. Es ist dies die posthämorrhagische akute und chronische Anämie, die sich im Experiment gut imitieren läßt. Ihre Entwicklung ist an einen einmaligen oder mehrmaligen Blutverlust gebunden, wobei der Ort der Hämorrhagie ohne Bedeutung ist. Es können enorm hochgradige Anämien durch länger dauernde Blutverluste entstehen (Grawitz bis 400000 Erythrocyten). Typisch für sie - als Reiz auf das Knochenmark - ist eine Leukocytose, Herabsetzung des Färbeindex, langsame Regeneration.

Bei meinen Versuchen erzeugte ich eine chronische und akute Anämie, das Resultat war ein verschiedenes, nur wenige konnten unter $30 \%$ Hämoglobin gebracht werden. Die Blutentnahme erfolgte aus dem Ohr, manchmal auch aus Femoralis und Carotis.

Als Beispiele führe ich in Tabelle IX an:

Tabelle IX.

Versuch III.

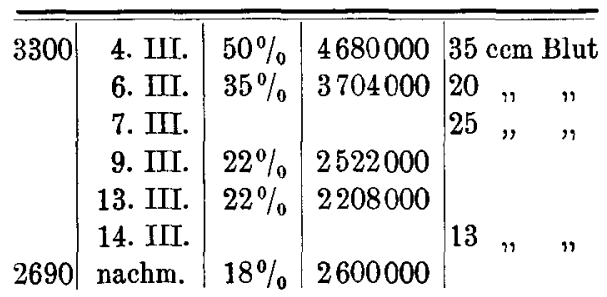

Versuch V.

\begin{tabular}{l|l|l|l|l|l}
\hline 2650 & 15. IV. & $44 \%$ & 4960000 & $\mathrm{ccm}$ Blut
\end{tabular} 2520 16. TV. $27 \% 2120000$

In sämtlichen Versuchen wurde eine Anämie erreicht, ihre Dauer ist, wie sich der Tabelle $\mathbf{X}$ entnehmen läßt, sehr verschieden.

Tabelle X.

\begin{tabular}{|c|c|c|c|c|c|}
\hline & $\begin{array}{l}\text { Gewichts- } \\
\text { abnahme }\end{array}$ & $\begin{array}{c}\text { Dauer der } \\
\text { Anämie }\end{array}$ & $\begin{array}{l}\text { Grad der } \\
\text { Anämie }\end{array}$ & $\begin{array}{l}\text { Hyper- } \\
\text { trophie }\end{array}$ & $\begin{array}{c}\text { Versuchs- } \\
\text { dauer }\end{array}$ \\
\hline I. & 700 & 18 Tage & $22 \%$ & vorhanden & $\dagger$ \\
\hline II. & 550 & $20 \quad$, & $14 \%$ & & $\dagger$ \\
\hline III. & 610 & 8 & $18 \%$ & & $\dagger$ \\
\hline IV. & 130 & 1 & $27 \%$ & & hält aus \\
\hline V. & 320 & 11 & $13 \%$ & & hält aus \\
\hline VI. & 85 & 1 & $34 \%$ & & hält aus \\
\hline VII. & 100 & $1 / 2$ & $39 \%$ & & $\dagger$ \\
\hline VIII. & 50 & 39 & $35 \%$ & & bält aus \\
\hline IX. & 40 & 25 & $32 \%$ & & hält aus \\
\hline $\mathrm{X}$. & 625 & 46 & $32 \%$ & & $\dagger$ \\
\hline
\end{tabular}


Ich lasse in Tabelle XI und XII die entsprechenden Drucksteigerungen nach der Kompression folgen.

Tabelle XI.

\begin{tabular}{r|c|c|c}
\hline \hline & $\begin{array}{c}\text { systolisch: } \\
\text { Höhe des Gipfel- } \\
\text { punktes }\end{array}$ & $\begin{array}{c}\text { diastolisch: } \\
\text { Höhe des Fuß- } \\
\text { punktes }\end{array}$ & Amplitude \\
\hline \hline I. & 8,5 & 6,5 & 2 \\
II. & 7,5 & 6 & 1,5 \\
III. & 7,5 & 7 & 0,5 \\
IV. & 6 & 9 & -3 \\
V. & 10 & 8 & 2 \\
VII. & 7 & 8 & -1 \\
VII. & 5,5 & 3 & 2,5 \\
VIII. & 3 & -1 & 4 \\
IX. & 3,5 & 3,5 & 0 \\
X. & 5,5 & 6,5 & -1 \\
\hline Mittel & 6,4 & 5,6 & 0,75 \\
Normal & 6,2 & 1,56 & 4,73
\end{tabular}

Tabelle XII.

\begin{tabular}{|c|c|c|c|c|c|c|c|}
\hline & \multicolumn{4}{|c|}{ Höchster Druck } & \multirow{2}{*}{\multicolumn{2}{|c|}{$\begin{array}{l}\text { Ausgangsdruck } \\
\text { erreicht nach } \\
\text { Minuten }\end{array}$}} & \multirow{3}{*}{$\begin{array}{l}\text { Verbalten bei } \\
180 \text { Minuten }\end{array}$} \\
\hline & \multicolumn{2}{|c|}{ systolischer } & \multicolumn{2}{|c|}{ diastolischer } & & & \\
\hline & $\begin{array}{l}\text { Maximum } \\
\text { nach } \\
\text { Minuten }\end{array}$ & $\begin{array}{c}\text { Maximum } \\
\text { beträgt } \\
\mathrm{mm}\end{array}$ & $\begin{array}{c}\text { Maximum } \\
\text { nach } \\
\text { Minuten }\end{array}$ & $\left|\begin{array}{c}\text { Maximum } \\
\text { beträgt } \\
\mathrm{mm}\end{array}\right|$ & systol. & diastol. & \\
\hline I. & sofort & 17,5 & sofort & 10 & 165 & - & $\dagger, \begin{array}{l}\text { ganz } \\
\text { langl. Kurve Pausen }\end{array}$ \\
\hline II. & 5 & 22 & 5 & 17,5 & 80 & - & $175^{\prime} \dagger$ \\
\hline III. & sofort & 25 & sofort & 17,5 & 55 & 99 & $\begin{array}{l}\dagger, \text { kaum noch } \\
\text { Schwankungen }\end{array}$ \\
\hline IV. & 40 & 19 & sofort & 11,5 & 75 & - & dentliche Kurve \\
\hline V. & sofort & 24 & sofort & 16 & nicht & rreicht & 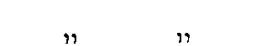 \\
\hline VI. & 2 & 27 & 5 & 17,5 & 30 & 85 & $n \quad n$ \\
\hline VII. & 10 & 13 & 10 & 9 & 35 & 30 & $\begin{array}{l}\text { vereinzelte Zuk- } \\
\text { kungen, }\end{array}$ \\
\hline VIII. & sofort & 18 & 25 & 16 & 30 & 35 & deutliche Kurve \\
\hline IX. & 5 & 17 & 5 & 15 & 125 & 170 & 11 \\
\hline $\mathrm{X}$. & 5 & 15,5 & 5 & 12 & 120 & 120 & $150^{\prime} \dagger$ \\
\hline $\begin{array}{l}\text { Mittel } \\
\text { Normal }\end{array}$ & & $\begin{array}{l}19,8 \\
19,9\end{array}$ & & $\begin{array}{l}14,2 \\
13,3\end{array}$ & & & \\
\hline
\end{tabular}

Mit Ausnahme von zwei Kurven zeigen sie dasselbe Verhalten wie die Normalen. Die eine (VI) zeigt einen sehr beträchtlichen Anstieg 


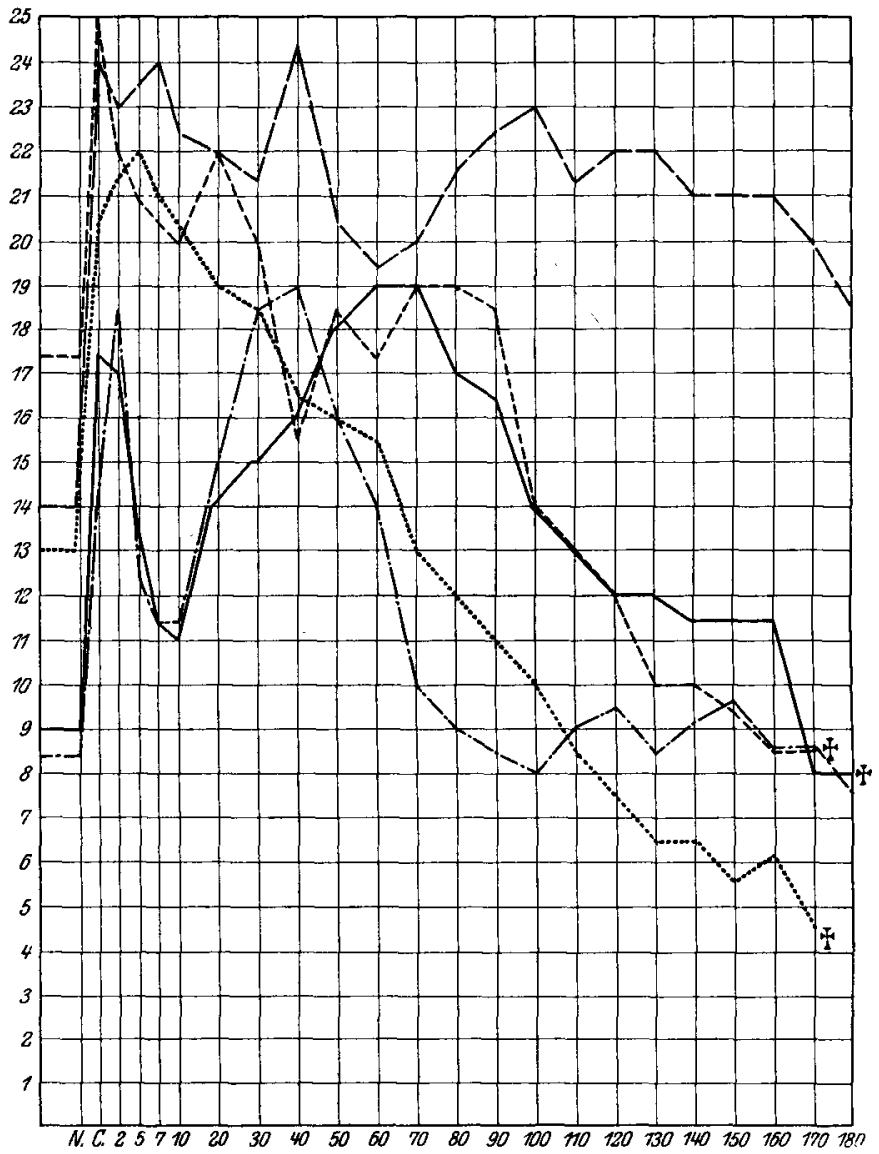

Fig. 7. Entblutungsanämien. Versuch $I \dagger$

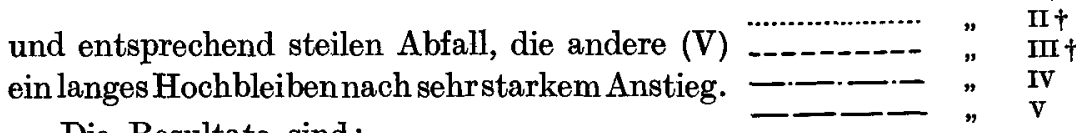

Die Resultate sind:

1. Normale Ausgangswerte.

2. Steigerung nach Kompression wie beim Normalen.

3. Stärkerer Anstieg des Fußpunktes (Diastole) und geringerer der Amplitude. Diese erfährt nach der Kompression eine ganz minimale Steigerung, sie ist etwa 6 mal kleiner als beim Normalen und in drei Fällen sogar verkleinert.

4. Rückkehr zu den Ausgangswerten schwankend.

5. In keinem Falle rascher Exitus, in 5 Fällen zwischen 100-180', - In 3 Fällen waren die Blutdruckschwankungen und die systo- 


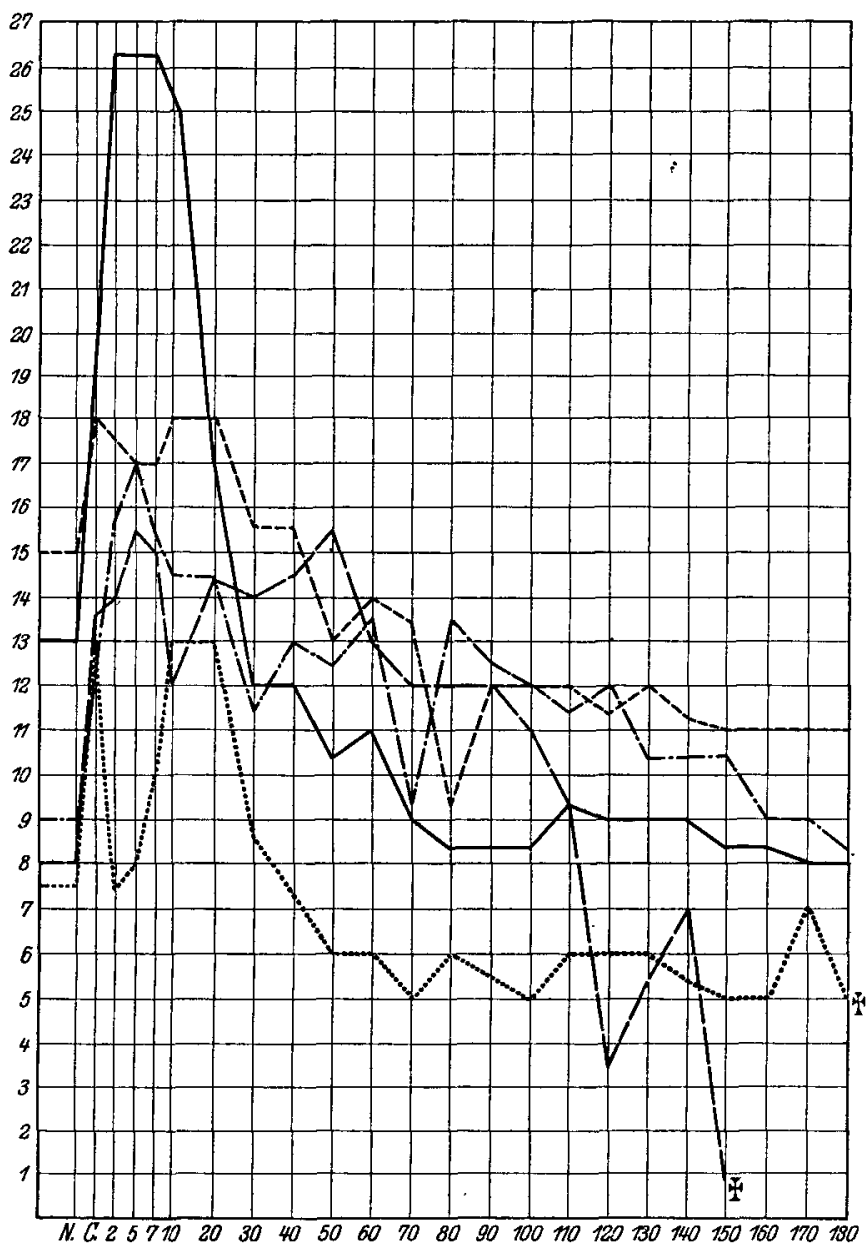

Fig. 8. Entblutungsanämien.

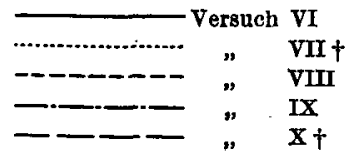

lischen Erhebungen so klein, die Pausen so groß, daß man von Exitus zu sprechen berechtigt ist.

6. Maximum ist meistens bald nach der Kompression erreicht.

Die Kurven zeigen folgende Eigenschaften:

I. Bei $2^{\prime}$ Bigeminus, sonst Kurve regelmäßig. Von $120^{\prime}$ an sukzessive Kraft der Systole abnehmend. Verlängerung der Pausen.

II. Bei $2^{\prime}$ Bigeminus. Gegen Schluß inäqual werdend, längere Pausen, teilweise Alternans. Systole abnehmend. 
III. Bei Kompression einzelne unruhige Schläge. $20^{\prime}$ und $25^{\prime}$ stärkere dikrote Zacke. 95' Extrasystole. 100' einzelne Bigemini. Nach $175^{\prime}$ rasches Sinken unter Inäqualwerden.

IV. Nur Respirationsschwankungen.

V. Nach Kompression Bigeminus, sonst ohne Besonderheiten.

VI. Immer regelmäßig.

VII. Von $50^{\prime}$ an schwächer werdend. Extrasystole, häufig Alternans.

VIII. Nach Kompression Extrasystole, später von $2^{\prime}$ an immer regelmäßig. Kleine, aber immer deutliche Kurve.

IX. Immer regelmäßig.

X. Zuerst nach Kompression Extrasystole, dann regelmäßig. Von $60^{\prime}$ an absinkend unter Pausenverlängerung.

\section{Gruppe V.}

(Vgl. Fig. 9 u. 10 und Tabelle XIX auf S. 342.)

In einer letzten Gruppe erzeugte ich durch Applikation verschiedener Blutgifte oder durch Kombination von Entblutung mit Phenylhydrazininjektionen Anämien. Den Effekt zeigt die Tabelle XIII.

Tabelle XIII.

\begin{tabular}{|c|c|c|c|c|c|}
\hline & $\begin{array}{l}\text { Gewichts- } \\
\text { verluste }\end{array}$ & $\begin{array}{c}\text { Dauer der } \\
\text { Anämie }\end{array}$ & $\begin{array}{l}\text { Grad der } \\
\text { Anämie }\end{array}$ & $\begin{array}{l}\text { Hyper- } \\
\text { trophie }\end{array}$ & Modus der Anämie \\
\hline I. & 440 & 6 Tage & $28 \%$ & & $\begin{array}{l}\text { Sapotoxin tägl. } 0,002 \text { intra- } \\
\text { venös }\end{array}$ \\
\hline II. & 380 & $n$ & $10 \%$ & & $\begin{array}{l}\text { Toluylendiamin u. Phenyl- } \\
\text { hydrazin }\end{array}$ \\
\hline III. & 200 & 18 & $20 \%$ & vorhanden & $\begin{array}{l}\text { Sapotoxin, Toluylendiamin } \\
\text { und Phenylhydrazin }\end{array}$ \\
\hline IV. & 270 & 8 & $15 \%$ & & $\begin{array}{l}\text { Blutentnahme und Phenyl- } \\
\text { hydrazin }\end{array}$ \\
\hline $\mathrm{V}$. & 250 & 9 & unter $10 \%$ & & do. \\
\hline VI. & 330 & 11 & $20 \%$ & & do. \\
\hline VII. & 450 & 16 & $17 \%$ & & do. \\
\hline VIII. & 470 & 17 & $13 \%$ & & do. \\
\hline IX. & 200 & 18 & $17 \%$ & & do. \\
\hline $\mathrm{X}$ & 220 & 17 & $13 \%$. & & do. \\
\hline
\end{tabular}

Die Druckveränderungen nach der Kompression zeigen die Tabellen $\mathrm{XIV}$ und $\mathrm{XV}$. 
Tabelle XIV.

\begin{tabular}{r|c|c|c}
\hline & $\begin{array}{c}\text { Systolisch: } \\
\text { Höhe des Gipfel- } \\
\text { punktes }\end{array}$ & $\begin{array}{c}\text { Diastolisch: } \\
\text { Höhe des Fuß- } \\
\text { punktes }\end{array}$ & Amplitude \\
\hline I. & 4 & 2 & 2 \\
II. & 6 & 3,5 & 2,5 \\
III. & 5 & 2 & 3 \\
IV. & 8 & 7,5 & 0,5 \\
V. & 6 & 5 & 1 \\
VI. & 0,5 & 2 & $-1,5$ \\
VII. & 8,5 & 6 & 2,5 \\
VIII. & 7 & 7 & 0 \\
IX. & 9 & 2 & 7 \\
X. & 4 & 2 & 2 \\
\hline Mittel & 5,8 & 3,9 & 1,9 \\
Normal & 6,2 & 1,56 & 4,7
\end{tabular}

Tabelle XV.

\begin{tabular}{|c|c|c|c|c|c|c|c|}
\hline & \multicolumn{4}{|c|}{ Höchster Druck } & \multirow{2}{*}{\multicolumn{2}{|c|}{$\begin{array}{l}\text { Ausgangsdruck } \\
\text { erreicht nach } \\
\text { Minuten }\end{array}$}} & \multirow{3}{*}{$\begin{array}{l}\text { Verhalten bei } \\
180 \text { Minuten }\end{array}$} \\
\hline & \multicolumn{2}{|c|}{ systolischer } & \multicolumn{2}{|c|}{ diastolischer } & & & \\
\hline & $\begin{array}{c}\text { Maximum } \\
\text { nach } \\
\text { Minuten }\end{array}$ & $\begin{array}{l}\text { Maximum } \\
\text { beträgt } \\
\text { mm }\end{array}$ & $\begin{array}{c}\text { Maximum } \\
\text { nach } \\
\text { Minuten }\end{array}$ & $\begin{array}{c}\text { Maximum } \\
\text { beträgt } \\
\text { mm }\end{array}$ & systol. & diastol. & \\
\hline I. & 25 & 20,5 & 25 & 15 & 80 & 105 & $\begin{array}{l}\text { deutliche, doch } \\
\text { schwache Kurve, } \\
\text { längere Pausen }\end{array}$ \\
\hline II. & 15 & 14,5 & 15 & 9 & - & - & $25^{\prime} \dagger$ \\
\hline III. & 20 & 16,5 & 35 & 12 & 65 & 70 & $90^{\prime} \dagger$ \\
\hline IV. & 2 & 19 & 2 & 13 & 95 & 95 & Exitus 180 \\
\hline V. & sofort & 21 & sofort & 14 & 25 & 40 & $145^{\prime} \dagger$ \\
\hline VI. & 45 & 18,5 & 35 & 16 & nicht & rreicht & deutliche Kurve \\
\hline VII. & 10 & 24 & 10 & 16 & 110 & 140 & $n \quad 9$ \\
\hline VIII. & 2 & 25 & 2 & 20 & 30 & 45 & $115^{\prime} \dagger$ \\
\hline IX. & sofort & 19 & 55 & 8,5 & 40 & 90 & $145^{\prime} \dagger$ \\
\hline $\mathrm{X}$ & 20 & 23 & 45 & 14,5 & 145 & 150 & deutliche Kurve \\
\hline ittel & & 20,1 & & 13,8 & & & \\
\hline Normal & & 19,9 & & 13,3 & & & \\
\hline
\end{tabular}

Die Kurven zeigen teilweise einen etwas rascheren und steileren Abfall als die Normalen. In einem Fall rascher Exitus bei relativem Hochbleiben der Kurve (II).

Die Schlüsse sind folgende:

1. Etwas geringere Ausgangswerte. 


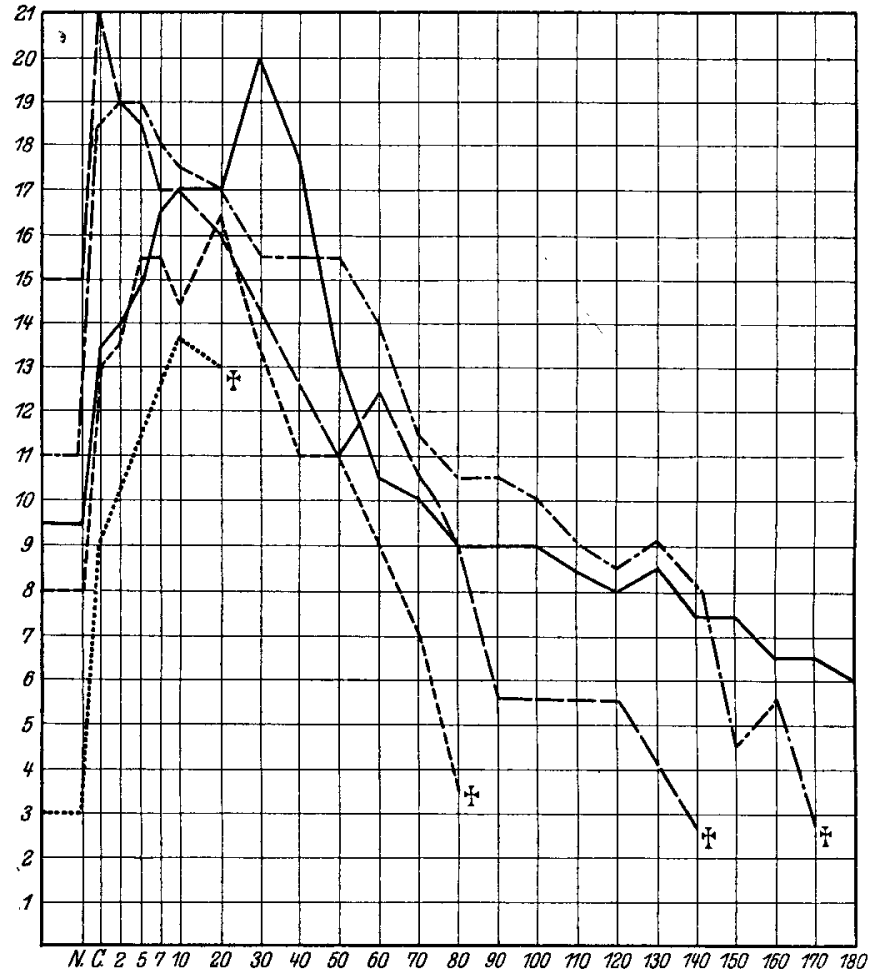

Fig. 9. Varia. Versuch I

2. Nach der Kompression systolische Erhebung wie beim normalen Tier.

3. Stärkerer Anstieg des Fußpunktes

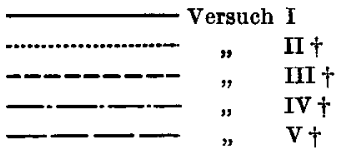
(Diastole), geringerer der Amplitude.

4. Verschiedene Rückkehr zu den Ausgangswerten.

5. In 6 Fällen Exitus, einmal ziemlich zu Beginn.

6. Maximaldruck in den wenigsten Fällen nach der Kompression erreicht.

Was die Kurvenbilder betrifft:

I. Nach Kompression deutliche dikrote Zacke, sonst regelmäßig.

II. Regelmäßig. Respirationsschwankungen, rasches Absinken.

III. Regelmäßig. Von $40^{\prime}$ an Zunahme der Pausen mit Senkung.

IV. Regelmäßig. Nach Kompression 2 Extrasystolen, von $80^{\prime}$ an zunehmende Pausen und Senkung.

V. Nach Kompression einzelne Extrasystolen, sonst ohne Besonderheiten. Sukzessives Sinken des systolischen Druckes. 


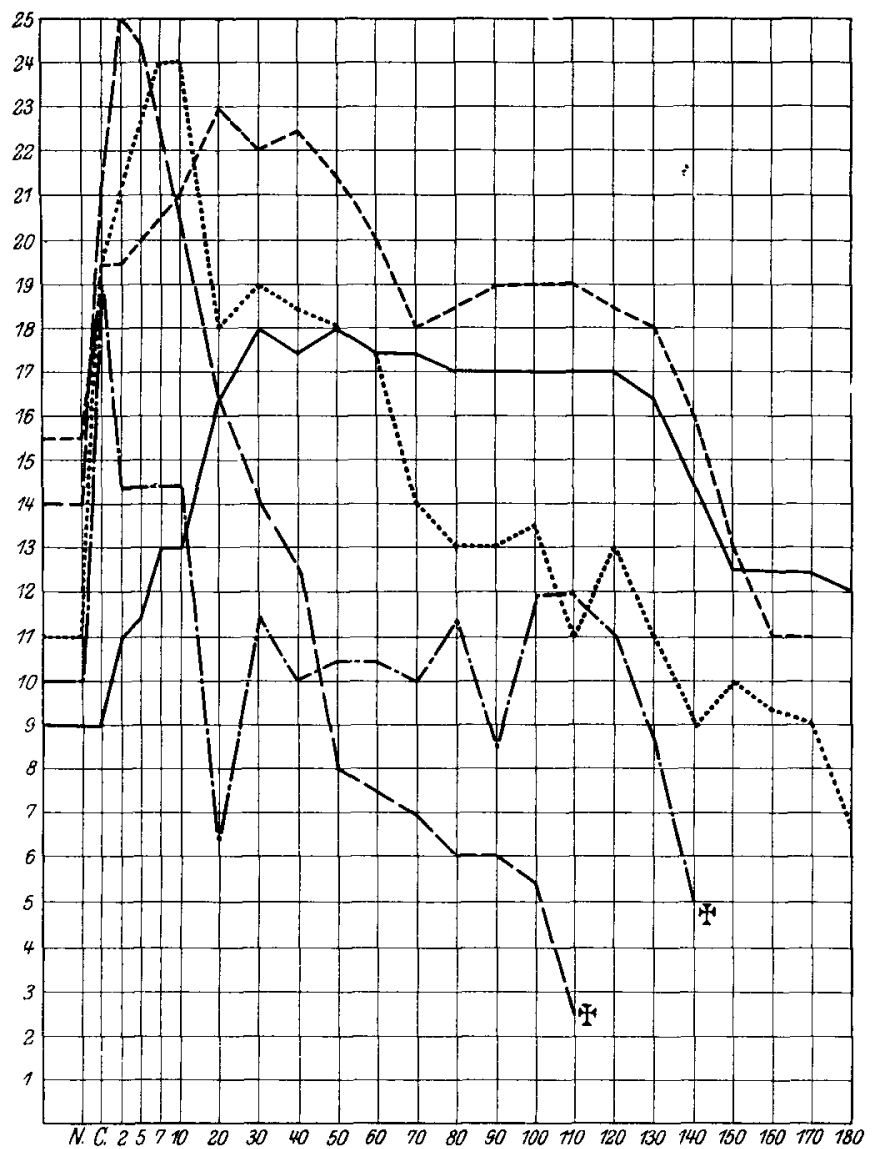

Fig. 10. Varia.

VI. Regelmäßig.

VII. Nach Kompression 2 Extrasystolen, bei

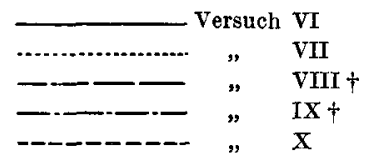
$7^{\prime} \mathrm{Bi}-$ und Trigemini, sonst regelmäßig.

VIII. Regelmäßig. Bei $35^{\prime}$ Trigemini. Von $50^{\prime}$ an längere Pausen. Zunehmende Drucksenkung.

IX. Nach Kompression verschieden starke dikrote Welle. Von $80^{\prime}$ an längere Pausen, Absinken des Druckes.

X. Regelmäßig.

Bevor ich auf die Zusammenfassung der Versuche eingehe, lasse jch"die Analyse der Gewichtsverhältnisse sowie die pathologisch-anatomische Untersuchung folgen. 
Das Verhalten des Herzens bei experimentellen Anämien.

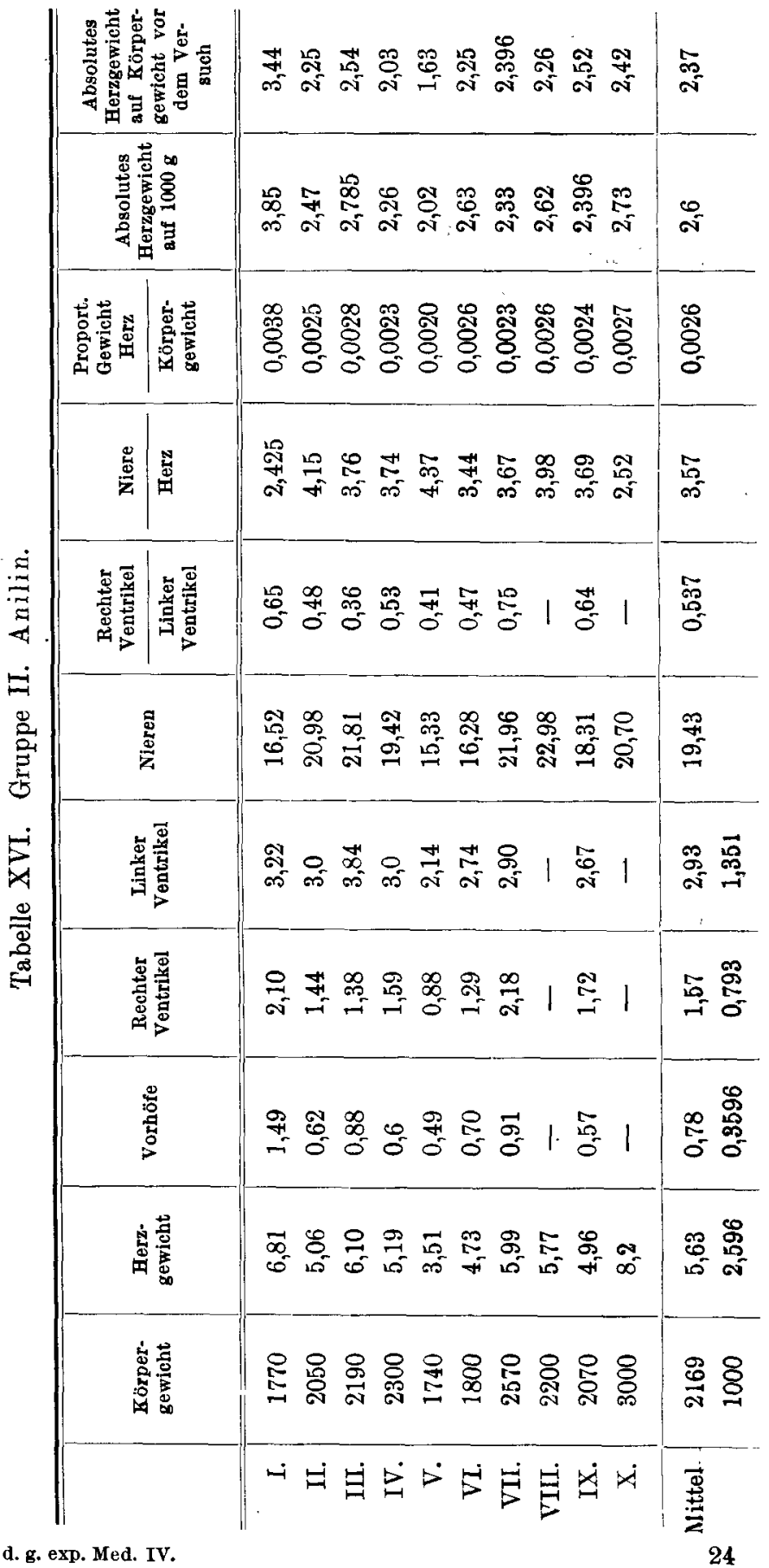




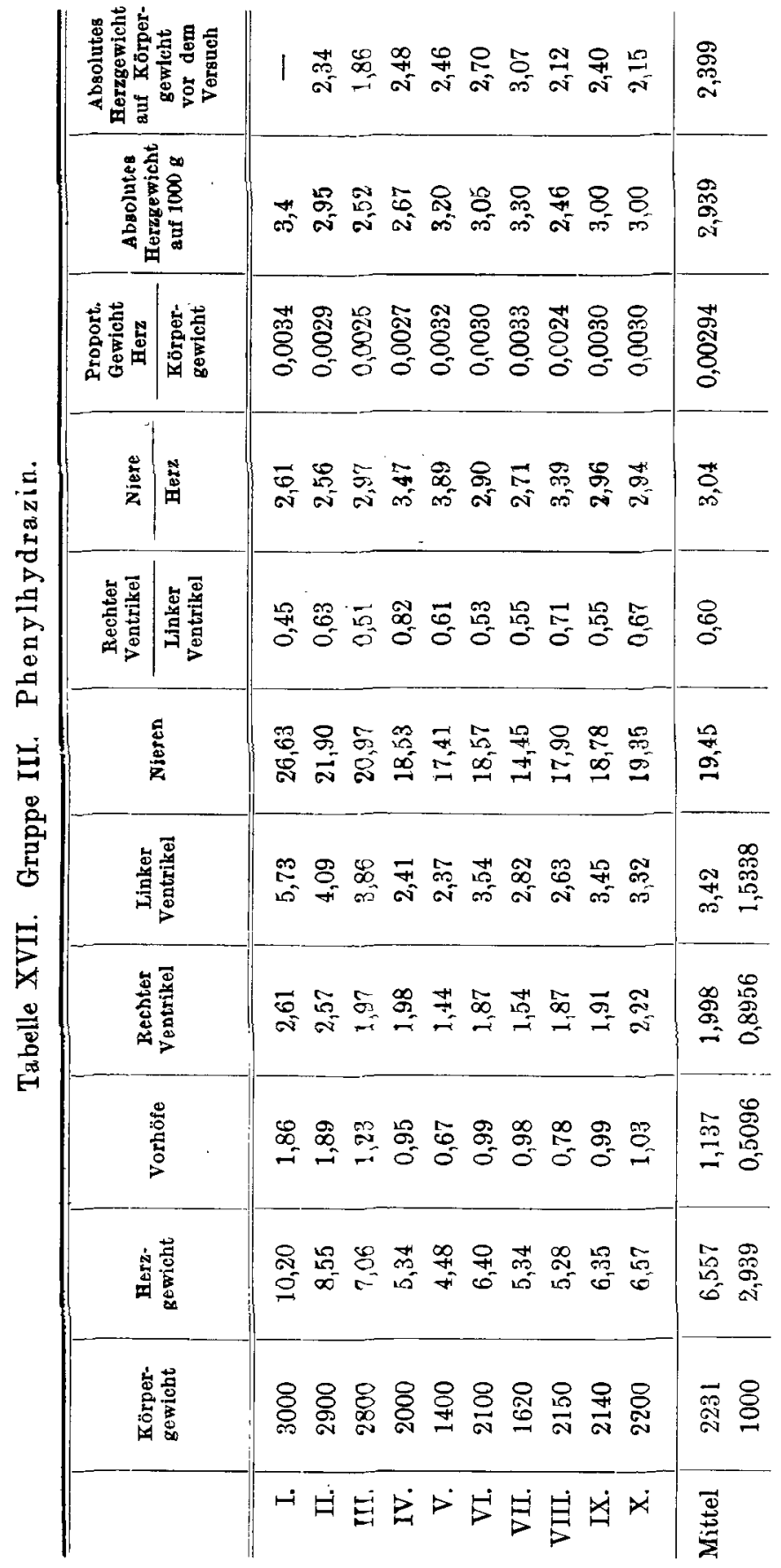


Das Verhalten des Herzens bei experimentellen Anämien.

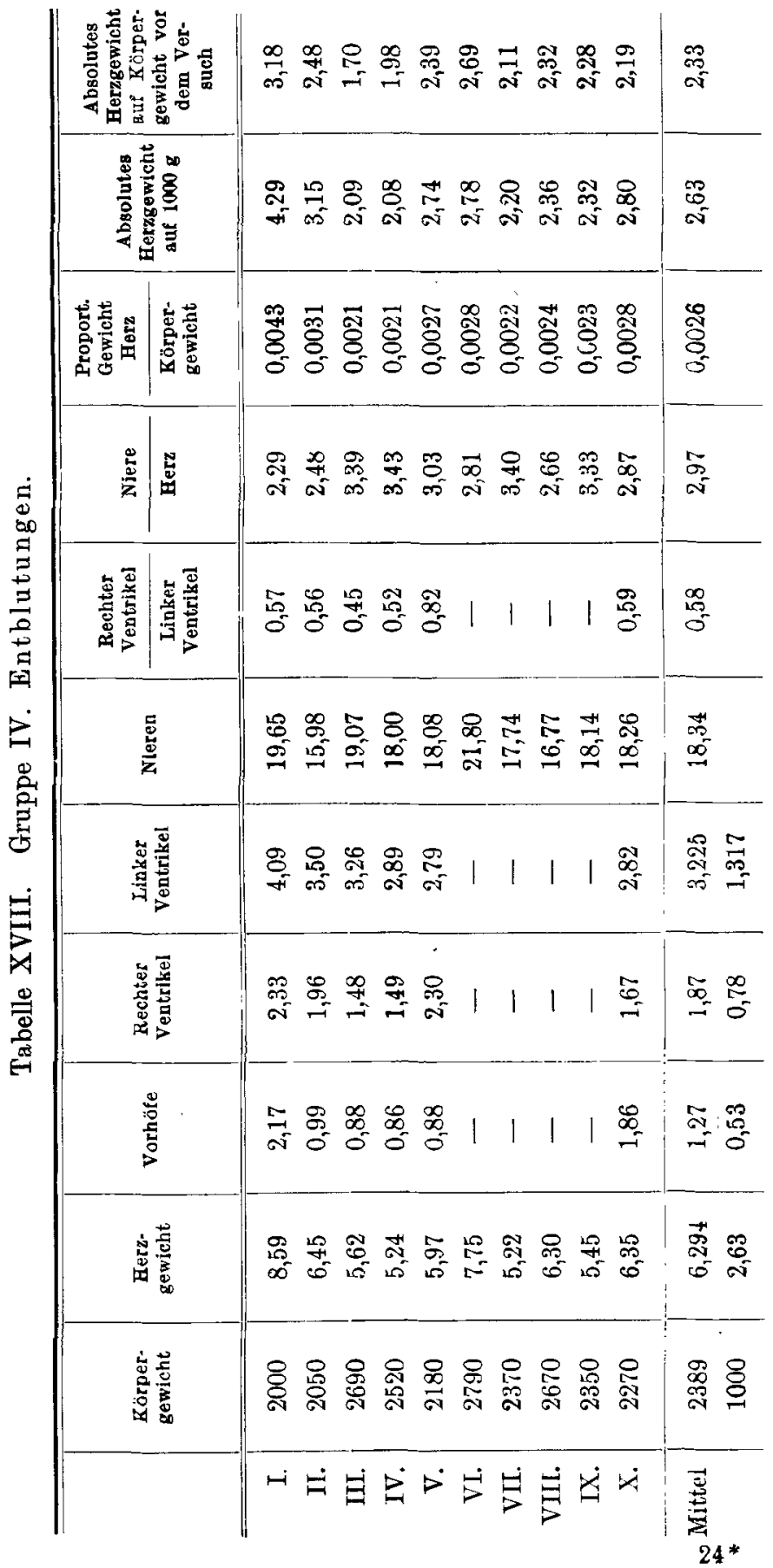




\begin{tabular}{|c|c|c|}
\hline 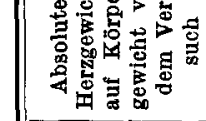 & 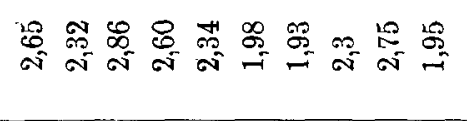 & $\begin{array}{l}\infty \\
\text { ar } \\
\text { i }\end{array}$ \\
\hline 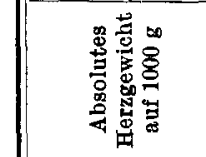 & 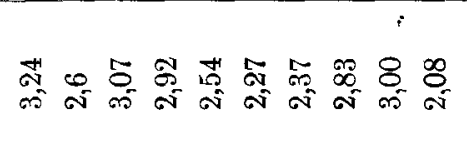 & \begin{tabular}{l}
$\infty$ \\
\multirow{\sigma}{*}{} \\
-
\end{tabular} \\
\hline 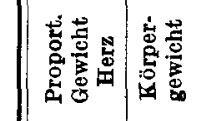 & 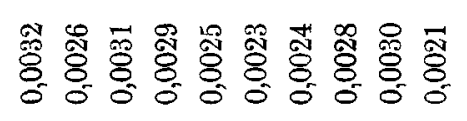 & 兑 \\
\hline 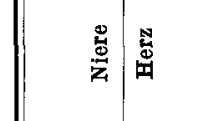 & 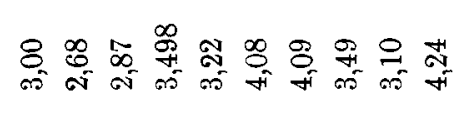 & $\underset{\infty}{\infty}$ \\
\hline 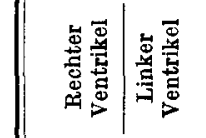 & 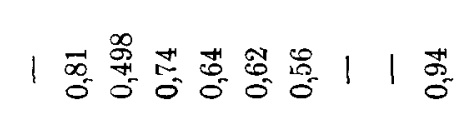 & $\begin{array}{l}\infty \\
\infty \\
0 \\
0\end{array}$ \\
\hline$\stackrel{\Xi}{\stackrel{\Xi}{\sharp}}$ & 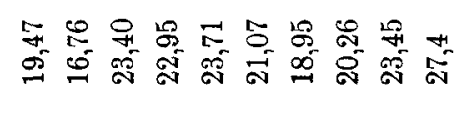 & $\underset{⿱ N}{\mathbb{N}}$ \\
\hline 总产咅 & 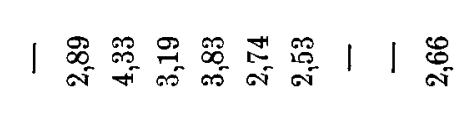 & 둥 \\
\hline 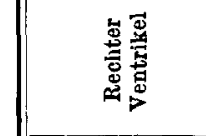 & 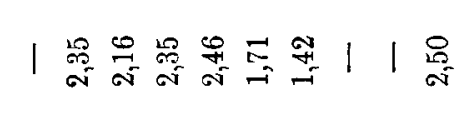 & 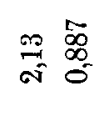 \\
\hline 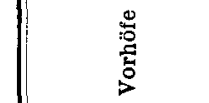 & 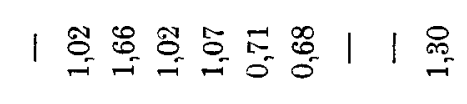 & $\stackrel{\sharp}{\sharp}$ \\
\hline 竧 & 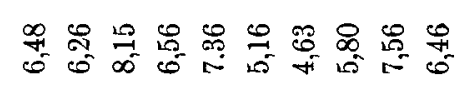 & 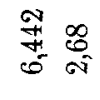 \\
\hline 悹惑 & 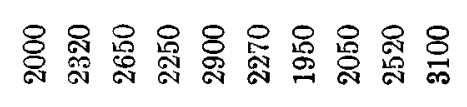 & 형 \\
\hline & 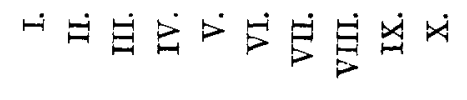 & 蛋 \\
\hline
\end{tabular}


Das Verhalten des Herzens bei experimentellen Anämien.

\begin{tabular}{|c|c|c|c|c|c|}
\hline 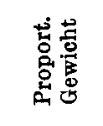 & $\underset{\delta}{\infty}{ }_{\delta}^{\infty}$ & 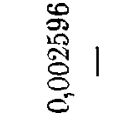 & $\underbrace{\mathscr{S}}_{\delta}$ & 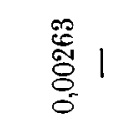 & $\underbrace{\infty}_{\delta}$ \\
\hline 莺 & 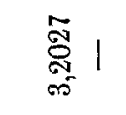 & $\underset{\infty}{\mathbb{E}} \mid$ & 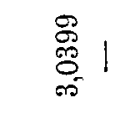 & $\begin{array}{l}\tilde{6} \\
\mathscr{6} \\
\text { o }\end{array}$ & $\underset{\infty}{\infty} \mid$ \\
\hline 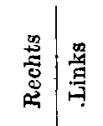 & $\begin{array}{l}\stackrel{N}{8} \\
\stackrel{8}{8} \\
\stackrel{\delta}{0}\end{array}$ & 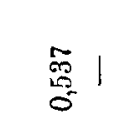 & $\underset{8}{\stackrel{8}{8}}{ }_{0} 1$ & $\begin{array}{ll}\stackrel{8}{\infty} & \\
0 & 1 \\
0 & 0\end{array}$ & $\begin{array}{l}\mathbb{R} \\
\substack{\mathbb{\infty} \\
0 \\
0 \\
0}\end{array}$ \\
\hline 总莺 & $\begin{array}{l}\infty \\
\infty \\
\infty \\
\infty\end{array}$ & $\begin{array}{c}\infty \\
\mathscr{S}_{0}\end{array}$ & 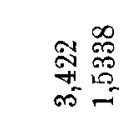 & 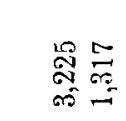 & 施 \\
\hline 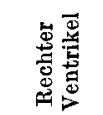 & 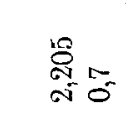 & 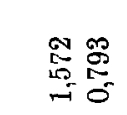 & 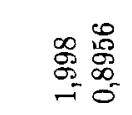 & 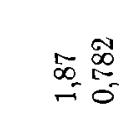 & $\begin{array}{l}\infty \\
\stackrel{\infty}{=} \\
0\end{array}$ \\
\hline $\begin{array}{l}\stackrel{0}{0} \\
\text { : } \\
0 \\
0 \\
0\end{array}$ & 范 & 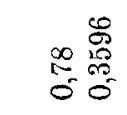 & $\begin{array}{l}58 \\
=8 \\
=0\end{array}$ & 총 & 承 \\
\hline 怘 & 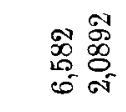 & 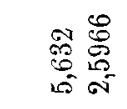 & 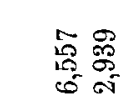 & 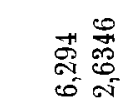 & 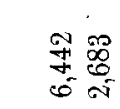 \\
\hline 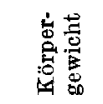 & 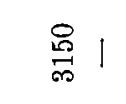 & $\underset{\infty}{\stackrel{\infty}{\sigma}} 1$ & $\overrightarrow{\mid \vec{N}} \mid$ & 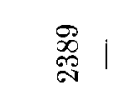 & 导 \\
\hline & 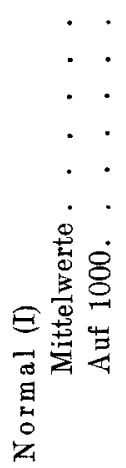 & 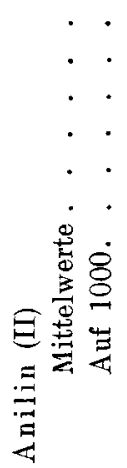 & 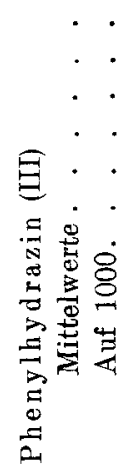 & 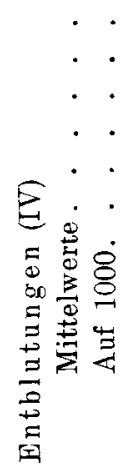 & 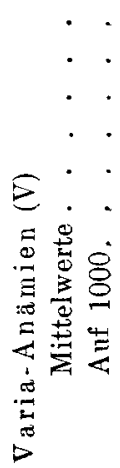 \\
\hline
\end{tabular}




\section{Herzgewichte.}

Durch W. Müller ist die Methode der Herzwägung in die Pathologie eingeführt worden. Zahlreiche Arbeiten, ich nenne die von Hirsch, Grober, Külbs, Romberg, Hasenfeld, Bergmann, Lützow, Wolfer, Stadler, haben ihre Brauchbarkeit für Pathologie, Biologie und experimentelle Medizin dargetan und wir besitzen in ihr ein genaues Maß, um objektiv über die Größe des Herzens und seiner Abschnitte urteilen zu können, mit ihrer Hilfe können auch isolierte Hypertrophien einzelner Herzabschnitte erwiesen werden.

Zum Vergleich mit meinen pathologischen Gruppen führe ich die von Romberg publizierten Mittelzahlen für Kaninchen und meine früher festgestellten Normalwerte in Tabelle XXI an. Die Zahlen Rombergs habe ich ebenfalls auf relative Werte pro 1000 Körpergewicht umgerechnet.

Tabelle XXI.

Romberg und Hasenfeld.

\begin{tabular}{|c|c|c|c|c|c|c|c|c|}
\hline & $\begin{array}{c}\text { Herz } \\
\text { in toto }\end{array}$ & $\begin{array}{l}\text { Linker } \\
\text { Ventr. }\end{array}$ & $\begin{array}{l}\text { Rechter } \\
\text { Ventr. }\end{array}$ & Septum & Vorhöfe & $\begin{array}{c}\text { Prop. } \\
\text { Gewicht }\end{array}$ & $\frac{\text { Rechts }}{\text { Links }}$ & $\frac{\text { Niere }}{\text { Herz }}$ \\
\hline $\begin{array}{l}\text { Mittel } 1919 . \\
\text { auf } 1000 .\end{array}$ & $\begin{array}{l}4,566 \\
2,374\end{array}$ & $\begin{array}{l}1,562 \\
0,814\end{array}$ & $\begin{array}{l}0,877 \\
0,457\end{array}$ & $\begin{array}{l}1,21 \\
0,6305\end{array}$ & $\begin{array}{l}0,703 \\
0,366\end{array}$ & $\begin{array}{c}0,00238 \\
-\end{array}$ & $\begin{array}{c}0,497 \\
-\end{array}$ & - \\
\hline \multicolumn{9}{|c|}{ Wolfer. } \\
\hline $\begin{array}{l}\text { Mittel } 3150 . \\
\text { auf } 1000 .\end{array}$ & $\left|\begin{array}{l}6,582 \\
2,0892\end{array}\right|$ & $\begin{array}{l}3,339 \\
1,06\end{array}$ & $\begin{array}{l}2,205 \\
0,7\end{array}$ & - & $\begin{array}{l}1,037 \\
0,3292\end{array}$ & $\begin{array}{l}0,00208 \\
0,00208\end{array}$ & $\begin{array}{l}0,669 \\
0,6603\end{array}$ & $\begin{array}{c}3,2027 \\
-\end{array}$ \\
\hline
\end{tabular}

Die Zahlen stimmen ziemlich miteinander überein, auch die Zahlen vom rechten und linken Ventrikel, wenn das Septumgebiet Rombergs halb nach rechts und links verteilt wird, da ich eben aus früher erwähnten Gründen auf Isolieren des Septums verzichtet hatte. Tangl, welcher sich mit der Herzhypertrophie nach künstlicher Aorteninsuffizienz beschäftigt hat, nimmt eine Hypertrophie an, wenn das relative Herzgewicht (auf 1000 Körpergewicht berechnet) den normalen Mittelwert von 2,58 bedeutend übersteigt, bzw. das Verhältnis $\frac{\text { Rechte und linke Niere }}{\text { Herz }}$ kleiner ist als 2,82, da dieses Verhalten nach Grawitz und Israel konstanter sein soll als das Proportionalgewicht.

Verglichen mit den Normalzahlen finden wir veränderte Herzgewichte bei Anämien. Im Durchschnitt sind die mittleren Körpergewichte bei Anämien etwa $1000 \mathrm{~g}$ unter dem der normalen und trotzdem ist ihr mittleres Herzgewicht dem Normalen kongruent. Noch deutlicher wird dieses Verhalten bei Umrechnung auf das relative Herzgewicht, dieses ist bei allen Gruppen höher als normal und über- 
steigt den Normalwert um $1 / 4$ oder noch mehr. (Vgl. die Tabellen sowie die Ubersichtstabelle.) Es würde nun naheliegen, diese Veränderungen der relativen Herzmasse auf die Körpergewichtsverluste, die bei den Tieren eingetreten sind, zu beziehen, denn gerade die Phenylhydrazingruppe zeigt die stärksten Gewichtsverluste und die stärkste Steigerung der Herzgewichte. Ich rechnete deshalb das relative Herzgewicht auf das Körpergewicht vor der Anämie um und suchte so zu bestimmen, ob dieses Verhalten dafür verantwortlich zu machen ist. Ich fand nun als Mittelzahlen:

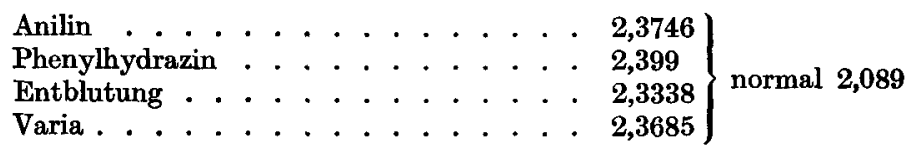

Zahlen; welche mit den normalen verglichen trotzdem eine Steigerung des Herzgewichtes deutlich erkennen lassen und ungefähr die Mitte zwischen Normal und ursprünglicher Berechnung halten. Wir dürfen deshalb, gestützt auf diese Umrechnung, annehmen, daB sich diese Veränderung nicht allein durch den Verlust an Körpergewicht erklären läßt. Die Einzelzahlen ergeben 7 mal einen Wert unter 2 und 3 mal einen Wert über 3.

Diese Zahlen weisen des bestimmtesten auf eine Hypertrophie hin; zu deren Ausrechnung legte ich die Postulate Tangls zugrunde und gleichzeitig sah ich zu, daß auch, umgerechnet auf das Körpergewicht vor der Anämie, diese Bedingungen erfüllt waren. Eine besondere Beachtung verdient das Verhalten des Quotienten $\frac{\text { Niere }}{\text { Herz }}$, denn es ist wohl sicher anzunehmen, daß beide Organe, als ständig tätig, sich im gleichen Sinne bei Körpergewichtsverlust - und auch im Hunger - verhalten. Es zeigen dies die für dieses Organ gewonnenen Zahlen, die ebenfalls gegenüber den Normalzahlen eine etwa dem Herzgewicht parallele Steigerung erkennen lassen. Ich lasse sie folgen, sie sind auf $1000 \mathrm{~g}$ Körpergewicht berechnet und in der zweiten Kolonne auf das Körpergewicht zu Beginn des Versuches bezogen.

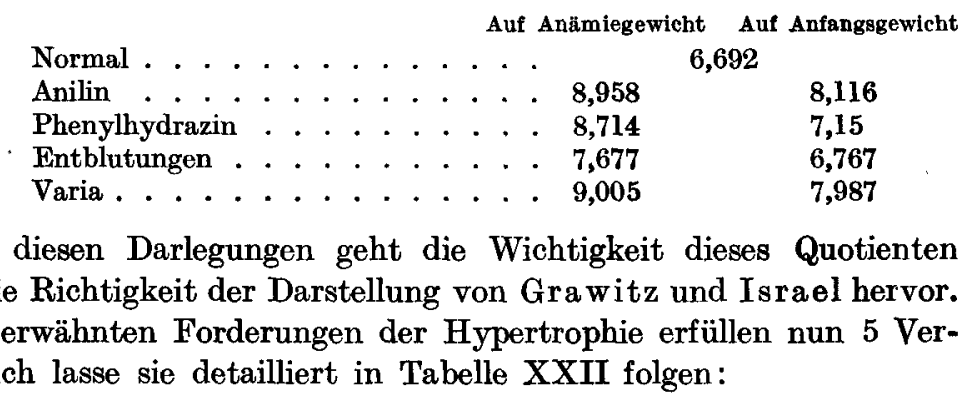


Tabelle XXII.

\begin{tabular}{|c|c|c|c|c|c|c|}
\hline & $\begin{array}{l}\text { Körper- } \\
\text { gewicht }\end{array}$ & $\begin{array}{c}\text { Herz } \\
\text { in toto }\end{array}$ & $\frac{\text { Niere }}{\text { Herz }}$ & $\begin{array}{l}\text { Prop. } \\
\text { Gewicht }\end{array}$ & $\begin{array}{c}\text { Absolutes } \\
\text { Herzgewicht } \\
\text { auf } \\
1000 \text { Körper- } \\
\text { gewicht }\end{array}$ & $\begin{array}{c}\text { Absolutes } \\
\text { Herzgewicht } \\
\text { auf Anfangs- } \\
\text { Körper- } \\
\text { gewicht } \\
\text { bezogen }\end{array}$ \\
\hline Anilin I . & 1770 & 6,81 & 2,43 & 0,00385 & 3,847 & 3,439 \\
\hline Phenylhydr.I & 3000 & 10,20 & 2,61 & 0,00340 & 3,4 & - \\
\hline , VII. & 1620 & 5,34 & 2,71 & 0,00329 & 3,29 & 3,069 \\
\hline Entblutung I & 2000 & 8,59 & 2,29 & 0,00429 & 4,29 & 3,181 \\
\hline Varia III . & 2650 & 8,15 & 2,87 & 0,00307 & 3,07 & 2,860 \\
\hline$\underset{\text { (Durchschnitt) }}{\text { Normal }}$ & 3150 & 6,58 & 3,20 & 0,00208 & 2,089 & - \\
\hline
\end{tabular}

Würde ich allein meine Mittelzahlen zugrunde legen, hätte ich in der Annahme einer Hypertrophie noch weiter gehen können, da ich als mittleren Quotienten $\frac{N}{H}=3,2$ fand; dann hätten sich in 13 Fällen Hypertrophien ergeben, doch wäre nur bei 6 derselben auch umgerechnet das Hypertrophiepostulat erfüllt gewesen. Bei Anlegung dieses strengen Maßstabes können 5 Herzen als hypertrophisch angesprochen werden und diese stimmen auch mit den Rom bergschen Zahlen überein. Im ïbrigen zeigt sich das Herzgewicht erhöht; bei der Anilingruppe in allen Fällen, niemals sehen wir ein Sinken unter 2 (häufig beim Normalen), das kleinste Herzgewicht geht kongruent mit dem stärksten Sinken des Körpergewiehtes. Phenylhydrazin zeigt die stärksten Gewichtsverluste, durchschnittlich starke Erhöhung des absoluten und des relativen Herzgewichtes sowie des Proportionalgewichtes. Bei den Entblutungen ist in 6 Fällen das absolute und relative Herzgewicht stärker erhöht; die akuten Anämien decken sich mit den Normalzahlen. Auch die Varia-Anämien zeigen starke Erhöhung sämtlicher Herzwerte - auch der umgerechneten -, doch paßt bei ihnen der $\stackrel{\mathrm{N}}{\mathrm{H}}$-Quotient nicht zur Hypertrophie.

Aus diesen Befunden läßt sich in $12 \%$ der Fälle eine sichere Hypertrophie annehmen, bei den anderen Versuchen hohe Herzgewichte, die auch umgerechnet an oberster Grenze des Normalen stehen, die mittleren Werte überragen und zur Hypertrophie hinneigen. Diese Befunde bei Anämie zeigen, daß das Herz bei diesen Blutveränderungen keine Verluste seiner Masse erleidet, im Gegenteil zunimmt und noch zur Hypertrophie fähig ist. Ähnlich verhält sich die Niere. Bei sämtlichen Gruppen zeigt sich dasselbe Verhalten, so daß dieser Vorgang Wirkung und Folge der Anämie ist, ohne daß toxische Wirkungen anzunehmen sind. 
Das Herz muß trotz Körpergewichtsverlusten Arbeit leisten, und zwar vermehrte Arbeit, wie aus dem gesteigerten Schlagvolumen hervorgeht; das Herz kompensiert durch beschleunigte und ausgiebigere Blutzirkulation bis zu einem gewissen Grade den Hämoglobinmangel (Morawitz, Mohr, Plesch, Bergmann). Welche Rolle einer Veränderung der Gefäße zukommt, ist schwer zu beurteilen, kommen doch bei Veränderung der Blutbeschaffenheit und bei Intoxikationen Verfettungen der Intima und Media vor (Ka uf mann). Inwiefern diese Veränderungen einwirkten, kann nicht bestimmt werden, da ich die Arterien nicht histologisch untersuchte. Jedenfalls würde auch durch eine Verfettung die Elastizität der Arterien nicht bedeutend verändert, und ist es doch speziell der Verlust dieser Eigenschaft, welcher das Herz zur Mehrarbeit zwingt (Arteriosklerose, Adrenalin). Ebenfalls nicht auf Rechnung pathologisch-anatomischer Veränderungen ist die Vermehrung der Herzmasse zu setzen, denn diese Befunde - Fett sind zu unbedeutend, nur eines der hypertrophischen Herzen zeigte etwas stärkere Verfettung (Phenylhydr. I), die anderen waren ziemlich frei. Diese Befunde decken sich mit den klinischen Erfahrungen Gautiers, welcher bei Anämie in einem Teil der Fälle Herzhypertrophie konstatierte. Diese Tatsachen bestätigt das Experiment und es liegt kein Grund vor, beim Menschen unter denselben pathologischen Bedingungen ein anderes Geschehen anzunehmen; daß eben in der menschlichen Pathologie ähnliche kontrollierende Untersuchungen nicht angestellt werden können, liegt in der Prognose der Anämie.

Die Frage, ob rechter oder linker Ventrikel oder Vorhöfe an der Hypertrophie speziell beteiligt sind, lösen die Tabellen, sie zeigen, daß die Zunahme gleichmäßig erfolgt. Das leichte Sinken des Quotienten $\frac{\mathrm{R}}{\mathrm{L}}$ zeigt an, daß der Hauptteil der Hypertrophie dem linken Ventrikel zukommt und er die meiste Mehrarbeit zu leisten hat, was mit Rücksicht auf die pathologische Physiologie der Anämien keiner weiteren Erklärung bedarf. Inwieweit noch eine relative Insuffizienz, welche durch die klinisch so häufig festgestellte Dilatation bedingt wäre, eine Rolle spielt, läßt sich nicht entscheiden. Es zeigt sich aus diesen Befunden wiederum, wie elegant und eindeutig die Methode der Herzwägung ist.

\section{Pathologische Anatomie.}

Für jeden Versuch wurde die histologische Untersuchung vorgenommen. Gefrierschnitte von rechtem und linkem Ventrikel, sowie von Vorhöfen und Nieren wurden gesondert mit Hämalaun-Eosin, van Gieson, Sudan- und Weigert-Elastinfärbung untersucht, für jeden Fall wurde eine Reihe von Schnitten durchgesehen. 
1. Anilin: Mit Hämalaun-Eosin wurden keine besonderen Veränderungen gefunden, in vereinzelten Fällen, entsprechend dem Fett, etwas Vakuolenbildung, sowie vereinzeltes Pigment. Degenerationsprozesse, interstitielle Prozesse, Nekrosen oder abnormer Pigmentgehalt konnten nicht eruiert werden. Nach van Gies on in Fall III und IV einzelne rote interstitielle Fasern, sonst nach dieser Färbemethode, sowie nach Elastin keine weiteren Veränderungen.

Uber das Verhalten des Fettes orientiert die Zusammenstellung in Tabelle XXIII ${ }^{1}$ ).

Tabelle XXIII.

\begin{tabular}{|c|c|c|c|c|}
\hline & Vorhöfe & Linker Ventrikel & Rechter Ventrikel & Niere \\
\hline I. & Etwas Fett & $\begin{array}{l}\text { Keine Deg. Etwas } \\
\text { Infiltr. }\end{array}$ & Wenig Infiltr. & Wenig Fett \\
\hline II. & Etwas Fett & $\begin{array}{l}\text { Deg. Wenig interst. } \\
\text { Fett }\end{array}$ & Fettspuren & Kein Fett \\
\hline III. & Kein Fett & $\begin{array}{l}\text { Deg. Wenig interst. } \\
\text { Fett }\end{array}$ & Fettspuren & Fettspuren \\
\hline IV. & Etwas Fett & $\begin{array}{l}\text { Deg. Wenig interst. } \\
\text { Fett }\end{array}$ & Fettspuren & Kein Fett \\
\hline V. & Kein Fett & Fettspuren & Fettspuren & $\begin{array}{c}\text { Kaum Fett. Spuren } \\
\text { v. Deg. in Tub. recti }\end{array}$ \\
\hline VI. & Etwas Fett & $\begin{array}{l}\text { Deg. Etwas interst. } \\
\text { Fett }\end{array}$ & Wenig Infiltr. & $\begin{array}{l}\text { Etwas Fett auch in } \\
\text { Glomerulis }\end{array}$ \\
\hline VII. & Kaum Fett & Wenig Infilt. Deg. & Etwas Infiltr. & Etwas Infiltr. \\
\hline VIII. & Kaum Fett & Wenig Infiltr. Deg. & Etwas Infiltr. & $\begin{array}{c}\text { Etwas Fett, Deg. } \\
\text { angedeutet }\end{array}$ \\
\hline IX. & Kaum Fett & Wenig Infiltr. Deg. & Etwas Infiltr. & Glom. etwas Fett. \\
\hline $\mathrm{X}$. & Etwas Fett & Wenig Infiltr. Deg. & Etwas Infiltr. & $\begin{array}{l}\text { Etwas Fett in Glom. } \\
\text { Tub. recti, stellen- } \\
\text { weise fettige Deg. }\end{array}$ \\
\hline
\end{tabular}

In keinem Falle stärkere Verfettung, Fettdurchwachsung hält sich in sehr mäßigen Grenzen, und dort, wo sich Degeneration findet, ist dieselbe nur in Spuren vorhanden. In keinem Falle hätten die pathologisch-anatomischen Veränderungen einen Schluß auf Herzinsuffizienz zugelassen oder eine solche erklärt.

2. Phenylhydrazin. Dasselbe Verhalten sämtlicher Herzabschnitte und der Nieren bei den drei Färbungen wie bei der Anilingruppe, nur bei Fall I eine Myocarditis interstitialis mit Lymphocyteninfiltration. Diese Gruppe repräsentiert die stärksten und ausgeprägtesten Anämien, ihre Wirkung auf die Verfettung des Herzens illustriert die Tabelle XXIV.

1) Wo nichts Besonderes bemerkt ist, ist nur Fettdurchwachsung oder Fettinfiltration gemeint. 
Tabelle XXIV.

\begin{tabular}{|c|c|c|c|c|}
\hline & Vorhöfe & Linker Ventrikel & Rechter Ventrikel & Niere \\
\hline I. & Spuren & $\begin{array}{l}\text { Starke Verfettung, } \\
\text { herdweise Fettdege- } \\
\text { neration, auch im } \\
\text { Papillarmuskel }\end{array}$ & Wenig interst. Fett & Etwas Fett in Tub. \\
\hline II. & Spuren & $\begin{array}{l}\text { Sehr wenig Infiltr. } \\
\text { Deg. }\end{array}$ & Wenig interst. Fett & Fettspuren \\
\hline III. & Kein Fett & Etwas Infiltr. Deg. & do. & $\begin{array}{l}\text { Wenig Fett in Tub. } \\
\text { u. Glomerulis }\end{array}$ \\
\hline IV. & Kein Fett & do & Sehr wenig Infiltr. & $\begin{array}{l}\text { Wenig Fett, etwas } \\
\text { in Glom. }\end{array}$ \\
\hline V. & $\begin{array}{c}\text { Wenig } \\
\text { Fett }\end{array}$ & $\begin{array}{l}\text { Stärkere Fettinfiltr. } \\
\text { u. Deg. in großen u. } \\
\text { kleinen Tropfen }\end{array}$ & $\begin{array}{l}\text { Reichl. Infiltr., } \\
\text { stellenweise starke } \\
\text { Deg. }\end{array}$ & $\begin{array}{l}\text { Mäßig Fett in Glom. } \\
\text { Tub. Deg. zeigend }\end{array}$ \\
\hline VI. & $\begin{array}{l}\text { Wenig } \\
\text { Fett }\end{array}$ & $\begin{array}{l}\text { Etwas Infiltr. und } \\
\text { Deg. }\end{array}$ & $\begin{array}{l}\text { Reichl. Infiltr., sel- } \\
\text { ten etwas Deg. }\end{array}$ & $\begin{array}{l}\text { Reichl. Infiltr. } u \text {. } \\
\text { Deg. }\end{array}$ \\
\hline VII. & $\begin{array}{l}\text { Wenig } \\
\text { Fett }\end{array}$ & Wenig Infiltr. Deg. & Etwas Infiltr. & $\begin{array}{l}\text { Mäßig Fett, etwas in } \\
\text { Glomerulis }\end{array}$ \\
\hline VIII. & Spuren & Reichl. Deg. & $\begin{array}{c}\text { Reichl. feine Fett- } \\
\text { tropfen in Fibrillen }\end{array}$ & $\begin{array}{l}\text { Glom. u. Tub. } \\
\text { mäßig deg. }\end{array}$ \\
\hline IX. & $\begin{array}{l}\text { Wenig } \\
\text { Fett }\end{array}$ & Wenig Infiltr. Deg. & Wenig Infiltr. & Wenig Infiltr. \\
\hline $\mathrm{X}$. & Spuren & $\begin{array}{l}\text { Viel Infiltr., sehr } \\
\text { wenig Deg. in fei- } \\
\text { nen Tropfen }\end{array}$ & Wenig Infiltr. & Wenig Infiltr. Deg. \\
\hline
\end{tabular}

In drei Fällen würde die Herzinsuffizienz durch die pathologischanatomischen Befunde ihre Erklärung finden (I, V, VIII), doch nur in einem dieser drei war Insuffizienz im Versuchsverlauf nachzuweisen.

3. Entblutungen. Mit Hämalaun-Eosin, van Gieson, und Elastin keine besonderen Veränderungen der Vorhöfe, Ventrikel und Nieren, selten etwas bräunliche Pigmentierung, vereinzelte Vakuolenbildung, vereinzelt perinucleäre Aufhellung. In keinem Fall - auch nach Sudan nicht - für Insuffizienz genügende Veränderungen. Die Sudanfärbung ergibt folgendes Resultat (Tabelle XXV):

Tabelle XXV.

\begin{tabular}{c|c|c|c|c}
\hline & Vorhöfe & Linker Ventrikel & Rechter Ventrikel & Niere \\
\hline I. & $\begin{array}{c}\text { Etwas In- } \\
\text { filtr. u. }\end{array}$ & $\begin{array}{c}\text { Etwas Infiltr., wenig } \\
\text { feinkörnige Deg. }\end{array}$ & $\begin{array}{c}\text { Wenig feinkörnige } \\
\text { Deg., etwas Infil- } \\
\text { tration } \\
\text { II. }\end{array}$ & $\begin{array}{c}\text { Wenig Fett, etwas } \\
\text { in Tub. }\end{array}$ \\
$\begin{array}{c}\text { Etwas In. } \\
\text { filtr. u. } \\
\text { Deg. }\end{array}$ & $\begin{array}{c}\text { Einzelne Fettkörn- } \\
\text { chen. Deg. }\end{array}$ & $\begin{array}{c}\text { Degas. Infiltr. u. } \\
\text { Deg. }\end{array}$ & $\begin{array}{c}\text { Zieml. Fett, nament- } \\
\text { lich Tub. }\end{array}$
\end{tabular}


Tabelle XXV (Fortsetzung).

\begin{tabular}{|c|c|c|c|c|}
\hline & Vorhöfe & Linker Ventrikel & Rechter Ventrikel & Niere \\
\hline III. & $\begin{array}{l}\text { Viel Fett, } \\
\text { wenigDeg. }\end{array}$ & $\begin{array}{l}\text { Reichl. Infiltr., sel- } \\
\text { ten Deg. }\end{array}$ & $\begin{array}{l}\text { Wenig Infiltr., etwaș } \\
\text { Deg. }\end{array}$ & - \\
\hline IV. & $\begin{array}{l}\text { Etwas In- } \\
\text { filtr. }\end{array}$ & $\begin{array}{l}\text { Wenig Infiltr., } \\
\text { Spuren Deg. }\end{array}$ & Etwas Infiltr. & $\begin{array}{l}\text { Mäßig Fett, etwas in } \\
\text { Tub. }\end{array}$ \\
\hline V. & $\begin{array}{l}\text { Wenig } \\
\text { Deg. }\end{array}$ & $\begin{array}{l}\text { Etwas Infiltr., ver- } \\
\text { einzelte Körnchen } \\
\text { in den Fibrillen }\end{array}$ & Etwas Infiltr. & $\begin{array}{l}\text { Glom. wenig, Tub. } \\
\text { etwas Fett }\end{array}$ \\
\hline $\begin{array}{l}\text { VI. } \\
\text { VII }\end{array}$ & Kein Fett & Wenig Infiltr. & Wenig Infiltr. & Wenig Fett \\
\hline VII, & & $\begin{array}{l}\text { Ziemlich viel Deg., } \\
\text { etwas Infiltr. }\end{array}$ & $\begin{array}{l}\text { Mäßig feinkörnige } \\
\text { Deg. }\end{array}$ & Tub. etwas Fett \\
\hline VIII. & $\begin{array}{l}\text { Etwas } \\
\text { Fett }\end{array}$ & Etwas Infiltr. & $\begin{array}{l}\text { Etwas Infiltr. u. } \\
\text { Deg. }\end{array}$ & Wenig Infiltr. \\
\hline IX. & $\begin{array}{l}\text { Wenig } \\
\text { Infiltr. }\end{array}$ & $\begin{array}{l}\text { Infiltr. reichl., Deg. } \\
\text { reichl. in feinen } \\
\text { Tropfen }\end{array}$ & $\begin{array}{l}\text { Infiltr. reichl., Deg. } \\
\text { reichl. in feinen } \\
\text { Tropfen }\end{array}$ & Etwas in Tub. \\
\hline $\mathrm{X}$. & $\begin{array}{l}\text { Wenig } \\
\text { Infiltr. }\end{array}$ & Wenig Infiltr. & Wenig Infiltr. & Wenig Infiltr. \\
\hline
\end{tabular}

4. Varia-A nämien. Dasselbe Verhalten des Herzens und der Niere bei Hämaląun, van Gieson und Elastin.

In zwei Fällen wurde eine leichte Tubulonephritis gefunden. Die Fettveränderungen demonstriert die Tabelle XXVI.

Tabelle XXVI.

\begin{tabular}{|c|c|c|c|c|}
\hline & Vorhöfe & Linker Ventrikel & Rechter Ventrikel & Niere \\
\hline I. & Spuren & Wenig Infiltr. Deg. & Etwas Infiltr. & $\begin{array}{c}\text { Wenig Fett, etwas } \\
\text { hyal. Zyl. }\end{array}$ \\
\hline II. & $\begin{array}{l}\text { Etwas } \\
\text { Infiltr. }\end{array}$ & Etwas Infiltr. & Etwas Infiltr. & $\begin{array}{l}\text { Wenig Fett, Tubulo- } \\
\text { nephritis }\end{array}$ \\
\hline III. & $\begin{array}{l}\text { Etwas } \\
\text { Infiltr. }\end{array}$ & $\begin{array}{l}\text { Etwas Infiltr., sehr } \\
\text { wenig Deg. }\end{array}$ & Etwas Infiltr. & $\begin{array}{l}\text { Spuren Fett, hyal. } \\
\text { Zylinder, } \\
\text { Tubulonephritis }\end{array}$ \\
\hline IV. & Spuren & $\begin{array}{l}\text { Reichl. herdweise } \\
\text { Deg. }\end{array}$ & $\begin{array}{l}\text { Infiltr. u. Deg. } \\
\text { reichl. }\end{array}$ & $\begin{array}{l}\text { Etwas Infiltr., Tub. } \\
\text { teilweise fettig deg. }\end{array}$ \\
\hline V. & Spuren & $\begin{array}{l}\text { Wenig Infiltr., etwas } \\
\text { Deg. }\end{array}$ & Wenig Infiltr. & Wenig Infiltr. \\
\hline VI. & $\begin{array}{r}\text { Wenig } \\
\text { Fett }\end{array}$ & Wenig Infiltr. & Etwas Infiltr. & Wenig Fett \\
\hline VII. & $\begin{array}{l}\text { Etwas } \\
\text { Infiltr. }\end{array}$ & $\begin{array}{l}\text { Stellenweise Deg. in } \\
\text { feinen Tropfen }\end{array}$ & $\begin{array}{l}\text { Reichlich feines Fett } \\
\text { in Fibrillen }\end{array}$ & Wenig Fett \\
\hline VIII. & $\begin{array}{l}\text { Etwas } \\
\text { Infiltr. }\end{array}$ & Wenig Infiltration & Wenig Infiltration & Wenig Infiltration \\
\hline IX. & $\begin{array}{l}\text { Etwas } \\
\text { Infjltr. }\end{array}$ & Wenig Infiltr. & Wenig Infiltr. & Kaum Fett \\
\hline $\mathrm{X}$. & $\begin{array}{l}\text { Wenig } \\
\text { Infiltr. }\end{array}$ & Wenig Infiltration & Wenig Infiltration & Kaum Fett \\
\hline
\end{tabular}


Im ganzen ist die Ausbeute an pathologisch-anatomischen Veränderungen äußerst gering. Der Fettgehalt besteht meistens in interstitiellem Fett, das von den Gefäßen und vom subperikardialen Fettgewebe ausgeht. Nirgends erreicht die Fettdurchwachsung größere Ausdehnung, sie hält sich, wie die einige Male beobachtete Fettdegeneration, in sehr mäßigen Grenzen und führt nirgends zu Auseinanderdrängung und Auflockerung der Fibrillen. Bei Anilin finden sich keine Fettdegenerationen; bei Phenylhydrazin 3 mal starke, 2 mal geringe und im Rest keine; bei Entblutungen: keine in 3 Fällen, geringe in 5 Fällen und etwas reichlichere in 2 Fällen; bei Varia-Anämien: in 6 Fällen keine, in 3 Fällen wenig und nur in einem Fall etwas reichlicher. Die Veränderungen beziehen sich in erster Linie auf den linken Ventrikel, im rechten, sowie in den Vorhöfen sind sie, wenn vorhanden, noch geringgradiger.

Ebenfalls geringe Veränderungen zeigen die Nieren; hier findet sich in den seltensten Fällen etwas stärkere Fettdegeneration.

Aus diesen Befunden ergibt sich, daß bei experimentellen Anämien die Veränderungen der Niere und des Herzens sehr geringe sind, und daß wir in den seltensten Fällen auch bei hochgradiger Blutveränderung eine für die Herzinsuffizienz genügende Veränderung finden können.

Für die Kontrolle der Präparate, sowie für die Unterstützung bei Bearbeitung des pathologisch-anatomischen Teils spreche ich Herrn Prof. Hedinger in Basel meinen herzlichsten Dank aus.

Wenn wir den Zusammenhang der Herzfunktion mit den übrigen Symptomen betrachten und so die einzelnen Gruppen vergleichen, erhalten wir interessante Aufschlüsse. In erster Linie wirft sich die Frage auf, in wieviel pathologischen Fällen konnte ein Versagen des Herzens im Verlauf von 3 Stunden gefunden werden. Die Gruppenzusammenstellung (Tabelle XXVII) illustriert dieses Verhalten:

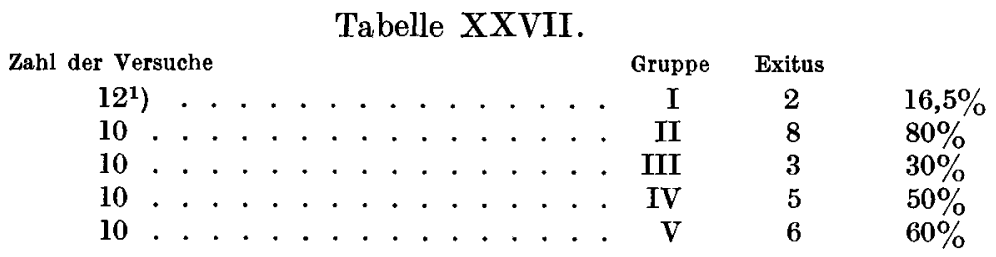

Es ergibt sich, daß bei den 4 pathologischen Gruppen ein viel größerer Prozentsatz der Tiere ad exitum kam, und es läßt sich daraus ohne weiteres eine Insuffizienz des Herzens bei Anämie entnehmen. In welcher Beziehung stehen nun diese Versuche mit dem Grad und

1) Drei Versuche wurden etwas vorher unterbrochen bei schöner Kurve. 
der Dauer der Anämie, sowie mit dem im Verlaufe des Versuches eingetretenen Gewichtsverluste? Folgende Zusammenstellungen in Tabelle XXVIII klären diese Verhältnisse:

Tabelle XXVIII.

I.

\begin{tabular}{|c|c|c|c|c|c|}
\hline \multirow{2}{*}{$=\frac{\begin{array}{c}\text { Hämoglobin- } \\
\text { gehalt }\end{array}}{0 \text { bis } 10 \%}$} & \multicolumn{5}{|c|}{ Versuche } \\
\hline & 6 & davor & ad & xitum & 6 \\
\hline $11 " 20 \%$ & 20 & $n$ & $"$ & $n$ & 10 \\
\hline \multirow{3}{*}{$\begin{array}{r}21 \text { " } 30 \% \\
\text { uber } 30 \%\end{array}$} & 8 & $n$ & $"$ & $n$ & 4 \\
\hline & 6 & $"$ & $"$ & $n$ & 2 \\
\hline & 40 & & & & 22 \\
\hline
\end{tabular}

II. Dauer der Anämie.

\begin{tabular}{l|c|c|c|c|c}
\hline 1 Tag & 2-7 Tage & 8-14 Tage & 15-21 Tage & 22-28 Tage & darüber \\
\hline 3 mit $1+$ & 8 mit $6+$ & 12 mit $5+$ & 7 mit $5+$ & 4 mit $3+$ & 6 mit $2+$
\end{tabular}

III.

\begin{tabular}{|c|c|c|c|c|}
\hline \multirow{8}{*}{$\begin{array}{c}\text { Gewichtsverluste: } \\
\text { uber } 200 \mathrm{~g} \\
200-400 " \\
400-600 " \\
600-800 " \\
800-1000 " \\
\text { Gewichtszunahme: } \\
?\end{array}$} & \multicolumn{2}{|c|}{8 davon } & \multicolumn{2}{|c|}{3 ad exitun } \\
\hline & 16 & $n$ & $10 n$ & $\eta$ \\
\hline & 7 & $"$ & 4 & $"$ \\
\hline & 4 & $"$ & 3 & $"$ \\
\hline & 2 & $n$ & $1 "$ & $"$ \\
\hline & 2 & $"$ & $1 "$ & \\
\hline & 1 & & & \\
\hline & 40 & & 22 & \\
\hline
\end{tabular}

Bei 5 Versuchen ergab sich eine Hypertrophia cordis, 3 von diesen kamen ad exitum, woraus hervorgeht, daß die Hypertrophie das Herz nicht vor seinem deletären Ende schützt. Im pathologisch-anatomischen Teil wurden die relativ geringen Veränderungen hervorgehoben, nur bei 3 Versuchen, von denen 2 ausdauerten, wäre die Insuffizienz erklärt worden. Die Anilintiere mit der größten Mortalität zeigen die geringsten pathologischen Veränderungen, die Phenylhydrazintiere mit der geringsten Mortalität die größten. Bei den andern Gruppen finden sich wenig ausgesprochene Veränderungen.

Die Interpretation dieser Zahlenreihen ergibt: Die Herzkraft ist bei Anämie deutlich herabgesetzt, ihre Mortalitätsziffer ist höher. Die Herzkraft sinkt mit dem Fallen des Hämoglobingehaltes und kein Tier mit einem Hämoglobingehalt unter $10 \%$ hielt die Kompression 
aus, nach den oberen Hämoglobinzahlen zu verbessern sich die Herzkraftbedingungen.

Interessant ist in dieser Hinsicht die Phenylhydrazingruppe, dort ist die Insuffizienz am wenigsten deutlich und nur die drei Tiere mit sehr tiefem Hämoglobingehalt kamen ad exitum. Die Dauer der Anämie scheint von etwas geringerem Einfluß zu sein. Hervorzuheben ist, da $\beta$ die akuten (posthämorrhagischen) Anämien eine relativ gute Herzkraft aufweisen und da $\beta$ von diesen Tieren $2 / 3$ die Kompression ertrugen. Deutlicheren Einflu $\beta$ auf die Herzkraft scheint dagegen der Verlust an Körpergewicht zu besitzen, mit zunehmender Abnahme vermehrt sich auch die Zahl der zum Exitus gekommenen Tiere.

Ich will die Reservekraft des anämischen Herzens einer genaueren Analyse unterziehen, indem ich nach Edens (l. c.) zwischen Reservekraft, Ausdauer und Leistungsfähigkeit unterscheide. Unter Reservekraft versteht Edens die Kraft, die der Muskel über die zurzeit bestehende Durchschnittsleistung hinaus auf stärkste Reize momentan zu entwickeln vermag. Als Indicator der Reservekraft dient dann der Zuwachs des systolischen Druckes nach der Kompression (Tabelle XXIX).

Tabelle XXIX.

\begin{tabular}{|c|c|c|c|c|c|c|}
\hline & & $\begin{array}{c}\text { Druek vor } \\
\text { Eingriff }\end{array}$ & Differenz & $\begin{array}{c}\text { nach } \\
\text { Kompression }\end{array}$ & \multicolumn{2}{|c|}{ Maximum } \\
\hline Normal . & . & 12,6 & 6,2 & 18,8 & 19,9 & \\
\hline Anilin . & . & 13,35 & 7 & 20,3 & 23,7 & \\
\hline Phenylhydrazin & . . & 13,7 & 8,3 & 22 & 23,9 & \\
\hline Entblutung. . & . . & 11,45 & 6,4 & 17,85 & 19,8 & \\
\hline Varia. . & . . & 10,6 & 5,8 & 16,4 & 20,1 & \\
\hline
\end{tabular}

Es zeigt das, daß die momentane Leistungsfähigkeit (Reservekraft nach Edens) keine Einbuße erlitten hat, im Gegenteil teilweise noch größer ist als beim Normalen.

Die mittleren Anfangswerte entsprechen sich ziemlich. Wie schon hervorgehoben wurde, wird im Gegensatz zu den Normalen das Druck: maximum nicht sofort nach der Kompression, sondern häufig erst geraume Zeit nachher erreicht und zeigt dann die gleiche Höhe oder eine Steigerung über die Normalwerte.

Für die Beurteilung der Ausdauer haben wir 2 Anhaltspunkte.

1. Dauer der Druckerhöhung bis zur Rückkehr zu den Ausgangswerten. Es gibt uns das an, wie lange das Herz vermehrte Arbeit gegen den Widerstand $\mathrm{zu}$ leisten imstande war.

2. Verhalten des Herzens bei 180 Minuten, welches die Herzfunktion nach längerer Inanspruchnahme wiedergibt. Ad 1. Die Rückkehr zú den Ausgangswerten unterliegt bei allen Gruppen großen individuellen 
Schwankungen, es sind keine festen Beziehungen zwischen Anämie und Reservekraft zu finden. Es zeigt dies, daß aus diesem Verhalten des Blutdrucks, wie das im Vergleich mit dem Folgenden noch deutlicher wird, keine bindenden Schlüsse auf die Ausdauer (Kraft) des Herzens gezogen werden dürfen. Im ganzen sindd die Anämiekurven in ihrem Abfall etwas steiler. Ad 2. Wesentlich andere Verhältnisse ergeben sich bei Vergleich der Kurven bei 180 Minuten:

Grúppe I. Sämtliche Kurven (10) sehr deutlich. Diejenigen, die kurz vorher abgebrochen wurden, waren bei diesem Zeitpunkt sehr schön.

Gruppe II. Zwei Kurven deutlich und regelmäßig, eine schwach mit sehr großen Pausen, die andern ad exitum gekommen.

Grup pe III. Sämtliche bleibenden Kurven (7) deutlich, viele etwas längere Pausen zeigend.

Gruppe IV. Fünf Kurven deutlich, die andern zu Ende oder kaum noch Zuckungen zeigend.

Gru p pe V. Sechs Kurven zu Ende. Eine mit längeren Pausen und schwachen AusschIägen, drei Kurven deutlich.

Es ergibt sich daraus, daß diese 4 pathologischen Gruppen wesentlich anders reagieren und $\mathrm{da} ß$ ein größerer Prozentsatz der Tiere die Kompression nicht 3 Stunden ertragen hat, sondern vorher ad exitum gekommen ist oder undeutlichere Kurven liefert.

Bis jetzt wurde hauptsächlich die Veränderung der Systole berücksichtigt. Besondere Beachtung verdient das Verhalten der Diastole (des Fußpunktes) und der Amplitude, deren Schwankungen bis jetzt nicht ausführlicher erörtert wurden. Zur Vereinfachung bespreche ich diese Punkte zusammen. In ihrer Gesamtheit zeigen sie Abweichungen, die für die Herzkraftfrage von großer Bedeutung sein können.

Die Zahlen (Mittel) zeigen folgendes Verhalten (Tabelle XXX):

Tabelle XXX.

\begin{tabular}{|c|c|c|c|c|c|c|c|c|}
\hline & \multicolumn{4}{|c|}{ Diastole (FuBpunkt) } & \multicolumn{4}{|c|}{ Amplitude } \\
\hline & $\begin{array}{l}\text { Komp } \\
\text { vor }\end{array}$ & $\begin{array}{r}\text { ession } \\
\text { nach }\end{array}$ & $\begin{array}{l}\text { Differenz } \\
\text { im Mittel }\end{array}$ & $\underset{\text { wert }}{\text { Maximal- }}$ & $\begin{array}{l}\text { Kompr } \\
\text { vor }\end{array}$ & $\begin{array}{l}\text { ssion } \\
\text { nach }\end{array}$ & $\begin{array}{l}\text { Differenz } \\
\text { im Mittel }\end{array}$ & $\begin{array}{c}\text { Maxim.- } \\
\text { wert }\end{array}$ \\
\hline Normal & 10,0 & 11,056 & 1,5 & 13,3 & 2,6 & 7,3 & 4,7 & 6,6 \\
\hline Anilin & 8,5 & 13,3 & 4,8 & 16,9 & 5,3 & 6,9 & 1,6 & 6,8 \\
\hline Phenyl. . . & 9,5 & 15,3 & 5,8 & 17 & 4,2 & 6,7 & 2,5 & 6,9 \\
\hline Entblutungen & 6,5 & 12,05 & 5,6 & 14,2 & 4,9 & 5,7 & 0,8 & 5,6 \\
\hline Varia .... & 4,95 & 8,9 & 3,9 & 13,8 & 5,5 & 7,4 & 1,9 & 6,3 \\
\hline
\end{tabular}

Diese Zusammenstellung zeigt uns starke Abweichungen von der Norm und zwar bei allen Gruppen ziemlich gleichsinnig. Um dieses Verhalten darzustellen, habe ich bei sämtlichen Versuchen die Mittelwerte pro Zeitphase berechnet und die Resultate in Kurven gesetzt, welche uns ein relativ kläres Bild von diesen Veränderungen geben. 
Da diese Befunde Mittelwerte größerer Versuchsreihen sind, erhalten sie meiner Meinung nach größere Beweiskraft. Erschwerend fällt der Umstand in Betracht, daß häufig nach der Kompression Arhythmien eintreten, die bis zu einem gewissen Grade die Ausrechnung erschweren.

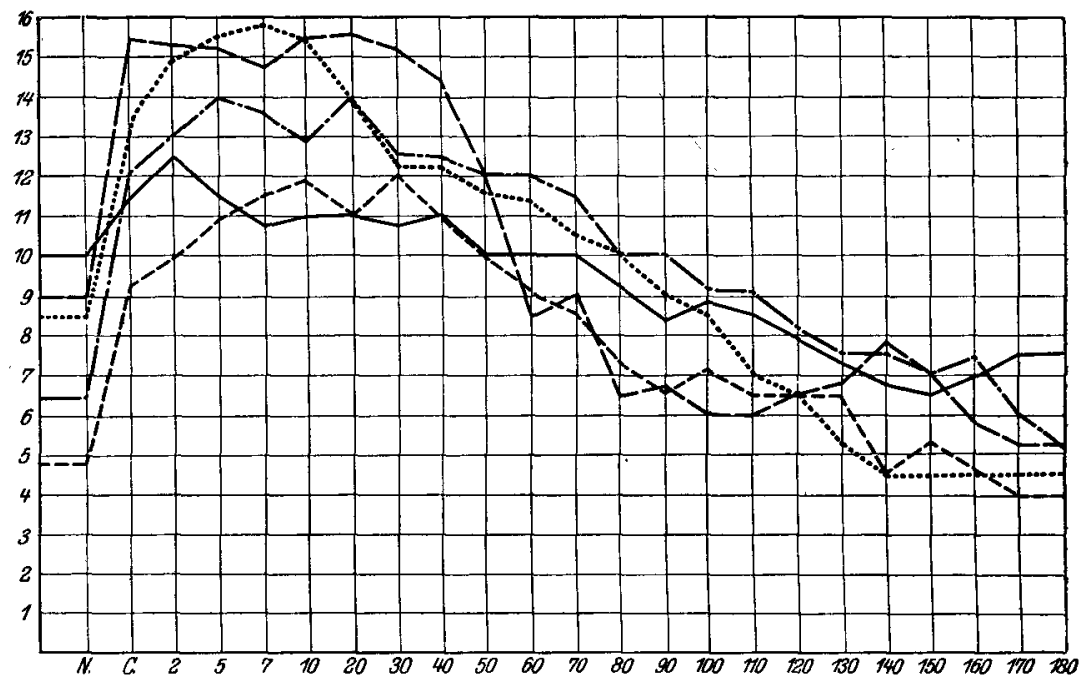

Fig. 11. Mittelkurve des Minimaldruckes der Carotis. (Diastole.)
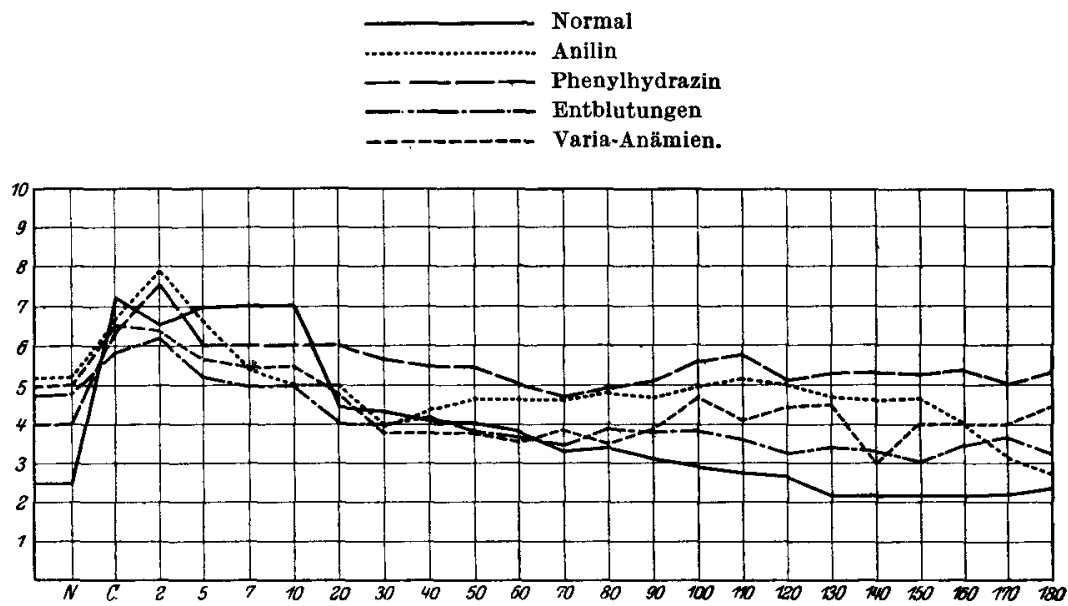

Fig. 12. Mittelkurve der Amplitude.

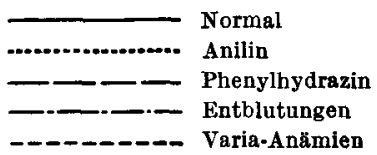


Der Vergleich dieser Kurven zeigt ein bestimmtes Abweichen von der Normalkurve.

I. Diastole: In sämtlichen Fällen ein tiefer stehender Fußpunkt im Beginn, der zum Teil beträchtlich unter dem normalen liegt. Anders nach der Aortenkompression, unmittelbar - aber auch sehr deutlich nach einigen Minuten - steigt der Fußpunkt sämtlicher Gruppen stark an, beträchtlich stärker und größtenteils absolut höher als der normale. In der ersten Stunde ein ständiges Höherbleiben - mit Ausnahme einer Gruppe, welche schon im Beginn einen sehr tiefen Fußpunkt aufwies -, besonders deutlich ist dieses Verhalten in Hinsicht auf die Ausgangsstellung. Dann beginnen die Kurven sich zu senken, aber im Unterschied zur normalen rascher und steiler, trotzdem wird bei allen Gruppen der Ausgangswert später erreicht, bei $180^{\prime}$ stehen alle unter diesem und unter dem normalen. Im ganzen: tiefere Ausgangswerte, stärkerer Anstieg, steilerer und tieferer Abfall, größere Exkursion der Totalkurve.

II. Amplitude: Auch hier zeigt sich ein anderes Verhalten. $\mathrm{Zu}$ Beginn ist die Amplitude bedeutend vergrößert, im Durchschnitt um etwa das Doppelte. Nach Kompression steigt sie weniger stark an, erreicht einen Gipfelpunkt, der trotz dem höheren Ausgangspunkt in zwei Kurven tiefer als der normale liegt und in 2 Kurven ihn kaum übersteigt. Es folgt rasche, doch unbedeutende Senkung und gegen die Mitte des Versuches Werte, welche bis zu Ende über den normalen liegen, kongruent mit dem Sinken der Diastole. (Vgl. die Kurven.)

Nach den Untersuchungen von $O$. Müller und Vöchting sind wir berechtigt, aus der Amplitude der Carotiskurve Rückschlüsse auf das Herzschlagvolumen zu ziehen, da die Verhältnisse am Herzen und in den peripheren Arterien - mit gewissen Einschränkungen - konform gehen. Er ist deshalb berechtigt, aus diesen Kurven den Schluß zu ziehen, daß das Schlagvolumen des Herzens bei experimentellen Anämien deutlich vergrößert ist. (Vgl. auch die Ergebnisse von Mohr.) Aus den Kurven ergibt sich ein gegen die Norm verändertes Verhalten. Schon vor der Kompression finden wir bei normaler Systole eine vergrößerte Amplitude (Schlagvolumen), welche auf eine Senkung der Diastole zurückzuführen ist. Nach Kompression ergibt sich ein stärkerer Anstieg der Diastolenwerte, ein geringerer der Amplitude; ich schließe daraus, daß das Herz die Fähigkeit, auf die Kompression wie das normale zu reagieren, verloren hat, und zwar ist hauptsächlich die Diastole verändert, denn diese steigt stark an, weil die diastolische Erweiterungsfähigkeit herabgesetzt ist. Das Herz hat in seiner Ausdehnungsfähigkeit i. e. in seiner Elastizität gelitten, jedenfalls geschädigt durch die durch die erhöhten Schlagvolumina bedingte vermehrte Arbeit und konsekutive Erweiterung (diastolisch). Für diese 
Annahme vermehrter Arbeit sprechen auch die Resultate der Herzwägung, welche große Herzgewichte, sowie einige Male Hypertrophie ergeben, und anders wie als Arbeitshypertrophie ist dieses Verhalten nicht zu denken.

Die Frage nach der Brauchbarkeit der Methode läßt sich, im Hinblick auf die gleichsinnigen Resultate von Romberg-Hasenfeld und Wolfer, entschieden bejahen. Da sie die Möglichkeit gibt, die Reservekraft und die Ausdauer des Herzens zu prüfen, war es berechtigt, sie unter anderen Versuchsbedingungen zu wiederholen, denn in ihrer Gesamtheit sind die Kurven imstande, uns wichtige Aufschlüsse über die Herzkraft zu geben. Weitere Versuche und Prüfungen könnten dabei nicht gemacht werden, namentlich die wichtige Frage der Erholung des Herzens konnte nicht berücksichtigt werden. Des fernern konnten, da es sich um große Versuchsreihen handelte, nicht Tiere eines Wurfs verwendet werden.

Das negative Resultat der pathologisch-anatomischen Untersuchung wurde erwähnt. Es können deshalb auch diese Versuche, da kaum Herzverfettung vorhanden war, nicht mit denen von Hase nfeld, Fenyvessy und Rothberger verglichen werden, sondern sie bilden, indem sie das „Anämieherz" prüfen, eine Erweiterung.

Wir fanden, daß die Anämie die Reservekraft, speziell die Ausdauer des Herzens schädigt und daß schwerste Anämien (unter 10\%) zu einer totalen Insuffizienz führen. Ein wichtiges Moment ist die Veränderung der Diastole und der Amplitnde. Das vergrößerte Schlagvolumen führt zu vermehrter Arbeit und in einigen Fällen resultiert daraus eine Hypertrophie, besonders da ja häufig bei Anämie eine Pulsbeschleunigung ${ }^{1}$ ) beobachtet ist, welche ebenfalls die Herzarbeit vermehrt. Auf die Kompression reagiert das Herz anders, und erst bei den Maximalwerten, die bei den Anämien etwas später erreicht werden, ist das normale Verhältnis bis zu einem gewissen Grad wiederhergestellt.

Infolge dieser Elastizitätsveränderung kann sich das Herz mit seinem vergrößerten Schlagvolumen nicht wie das normale gesteigerten Anforderungen und Widerständen anpassen, es erlahmt bei höheren Ansprüchen früher. - Die negativen pathologisch-anatomischen Befunde zwingen, andere Momente für die Insuffizienz zu suchen, ich suche sie in der diastolischen Erweiterungsfähigkeit, wie auch Romberg und Hasenfeld (l.c.) bei ihren Aorteninsuffizienzversuchen, wenn auch unter anderen Bedingungen, dieses Moment hervorheben. Der Füllungszustand scheint Bedingungen zu schaffen,

1) Bei meinen Versuchen erhielt ich keine besonders beschleunigte Pulsfrequenz, die Zahlen deckten sich mit den normalen, so da $\beta$ ich auf deren Wiedergabe verzichte. 
die die Herzkraft beeinträchtigen, so würde vermehrte Arbeit und vermehrte Inanspruchnahme durch größere Füllung zu einem Aufbrauch der Herzkraft und $\mathrm{zu}$ einer Insuffizienz führen und würde somit die Aufbrauchstheorie eine experimentelle Stütze erhalten.

Die hohe Mortalitätsziffer der Anilingruppe legt den Gedanken nahe, daß es sich bei derselben noch speziell um Herzschädigungen handeln könnte. Wie eingangs erwähnt, finden sich mit Ausnahme der Beobachtung von Massini (1. c.) keine speziellen Herzschädigungen erwähnt und auch meine anatomischen Befunde dieser Gruppe sprechen nicht für diese Annahme, es müßte sich dann die Veränderung auf das Nervensystem, welches bei Anilinintoxikationen geschädigt werden kann, beziehen. Auch die Befunde der anderen Gruppen, wo ebenfalls durch andere anämisierende Manipulationen eine erhöhte Herzinsuffizienz resultierte, sprechen gegen diese Annahme und lassen den Hauptteil der Anämie und der Blutveränderung zufallen. Auch die anderen Gruppen zeigen nur anatomische Veränderungen, welche durch die Anämie bedingt sind.

Neben den Blutveränderungen spielen die durch sie bedingten Ernährungssțörungen eine wichtige Rolle für den Zustand der Organe, dadurch, daß das Herz bis zu einem gewissen Grade Störungen (O-Mangel) zu kompensieren sucht, arbeitet es unter andern Bedingungen und vermehrt, sowie jedenfalls unter schlechteren Ernährungsbedingungen, und darin sind die Ursachen der Insuffizienz zu suchen. Es ergibt sich, daß das Herz bei Anämien geschädigt ist, neben der Insuffizienz zeigt es pathologische Veränderungen seiner Masse und andere Reaktion auf maximale Belastung. Welche Rolle die Anämie in der menschlichen Pathologie spielt, soll nicht weiter diskutiert werden, daß sie nicht bedeutungslos sein kann, ergeben nebst klinischen Beobachtungen diese Versuche, die erweisen, daß, wenn auch nicht immer schwere anatomische Veränderungen vorhanden sind, eine funktionelle Schädigung vorliegt.

\section{Zusammenfassung.}

I. Die Reservekraft, speziell die Ausdauer des Herzens, ist bei experimentellen Anämien herabgesetzt, diese steht in Beziehung zu dem Grad der Anämie und der Abnahme des Körpergewichts.

II. Im Durchschnitt wurden bei den Anämien hohe absolute und relative Herzgewichte gefunden. Daraus geht hervor:

a) daß das Herz keine parallel dem Körpergewichtsverlust laufende Einbuße erleidet,

b) daß es im Gegenteil an Masse zunimmt und in einzelnen Fällen hypertrophiert,

c) daß diese Hypertrophie das Herz nicht vor Insuffizienz bewahrt. 
III. Durch anämische Zustände werden geringe anatomische Veränderungen des Herzmuskels hervorgerufen; diese zeigen sich ausschließlich in einer Verfettung, und zwar meistens in interstitieller Verfettung, selten in Fettdegeneration.

IV. Nur in einem der Fälle läßt sich die nachgewiesene Insuffizienz anatomisch erklären.

V. Das anämische Herz zeigt von der Norm funktionelle Abweichungen, diese bestehen in verminderter Diastole und vergrößerter Amplitude (i. e. Schlagvolumen). Im Gegensatz zum Normalen nimmt nach Kompression die Amplitude nur geringgradig zu, dagegen steigt die Diastole in stärkerem Maße an. Das Hauptmoment der Herzinsuffizienz muß dem veränderten diastolischen Verhalten (verminderte diastolische Füllung = verminderte Elastizität) zugeschrieben werden.

\section{Literaturverzeichnis.}

Albrecht, Der Herzmuskel. Berlin 1903.

Allb utt, Über die Folgen der Einwirkung von Überanstrengung und Gewalt auf das Herz und die großen Blutgefäße. Seitz. Monographie. Berlin 1875.

Aschoff und Tawara, Zit. nach Krehl, Marchand und Edens.

Balint, Experimentelle Untersuchungen über die Ursachen der Inkompensation bei Herzklappenfehlern. Deutsche med. Wochenschr. 1898, 1 u. 19.

Berger, Anatomische Untersuchungen des Herzens bei Pulsus irregul. perpet. Deutsches Archiv f. klin. Med. 112.

Blu mental und Morawitz, Experimentelle Untersuchungen über posthämorrhagische Anämien. Deutsches Archiv f. klin. Med. 92, 25.

de la Camp, Experimentelle Studien über akute Herzdilatation. Zeitschr. f. klin. Medizin 51, 1.

Cohnheim, Allgemeine Pathologie 1877-1881.

da Costa, Überreizung des Herzens. Seitz, Monographie.

Curschmann, Zur Lehre vom Fettherz. Archiv f. klin. Medizin 12, 193.

Dietlen, Größe und Lage des Herzens und ihre Abhängigkeit von physiologischen Bedingungen. Kongr. f. innere Medizin 23, 267.

Edens, Über Herzhypertrophie. Deutsches Archiv f. klin. Medizin 111, 288. Eichhorst, Spezielle Pathologie und Therapie 1895.

Ep pinger, Med. Klin. 1908.

Eppinger und Knaffl, Über Herzinsuffizienz. Zeitschr. f. experim. Pathol. u. Ther. 5, 71. 1908.

Forster, Zur Frage der Formveränderung der Herzmuskelkerne. Deutsches Archiv f. klin. Medizin 86, 499.

Fräntzel, Zit. nach Leyden.

v. Frey, Physiologische Bemerkungen über die Hypertrophie und Dilatation des Herzens. Deutsches Archiv f. klin. Medizin 46, 308.

Friedstein, Experimentelle Beiträge zur Kenntnis der perniziösen Anämie und zur Pathologie der roten Blutkörperchen. Fol. Hämat. Archiv 1911.

Gautier, Über die morphologischen Veränderungen des Herzens bei der Chlorose auf Grund klinischer Beobachtungen. Deutsches Archiv f. klin. Medizin $62,120$. 
Gerhardt, D., Herzklappenfehler. Nothnagels spezielle Pathol. u. Ther. 1913.

- Anpassungs. und Ausgleichvorgänge bei Krankheiten. Volkmannsche Vorträge 470 .

Grober, Herzmasse und Arbeit. Ergebn. f. inn. Medizin u. Kinderheilk. 3, 34.

- Über die Einwirkung dauernder körperlicher Leistung auf das Herz. Wiener med. Wochenschr. 1913; Zentralbl. f. inn. Med. 5, B96. 1913.

- Massenverhältnisse des Herzens bei künstlicher Arterienstarre. Kongr. f. inn. Med. 24. 1907.

- Untersuchungen zur Arbeitshypertrophie des Herzens. Archiv f. klin. Med. 91, 502.

Hasenfeld, Über die Leistungsfähigkeit der fettig entarteten AorteninsuffizienzHerzen. Berl. klin. Wochenschr. 1900, S. 1148.

Hasenfeld und Fenyvessy, Über die Leistungsfähigkeit des fettig entarteten Herzens. Berl. klin. Wochenschr. 1899, S. 80.

Heinz, Handbuch der experimentellen Pharmakologie und Pathologie 1904.

Heubner, Spiralwindung der Herzmuskelkerne. Archiv f. klin. Med. 88, 601.

Hirsch, Über die Beziehungen zwischen dem Herzmuskel und der Körpermuskulatur und über sein Verhalten bei Herzhypertrophie. Archiv f. klin. Med. 68, 55 u. 320.

Itami, Archiv f. experim. Pathol. u. Pharmakol. 60, 77.

Isaac und Möckel, Über experimentelle schwere Anämien durch Saponinsubstanzen. Kongr. f. inn. Med. 17, 471.

- Experimentelle Untersuchungen über die Einwirkung des Sapotoxins auf die hämatopoetischen Organe. Zeitschr. f. klin. Med. Yz.

Ka mi ner und Rohnstein, Über Phenylhydrazinanämie. Berl. klin. Wochenschr. 1900, Heft 31.

Karcher, Über die Fragmentation des Herzmuskels. Archiv f. klin. Med. 60, 67.

Ka ufmann, Lehrbuch der speziellen pathologischen Anatomie 1909.

Kelle, Ưber primäre chronische Myokarditis. Archiv f. klin. Med. 49, 442.

Kobert, Handbuch der Intoxikationen.

Kraus, Die klinische Bedeutung der fettigen Degeneration des Herzmuskels schwer anämischer Individuen. Berl. klin. Wochenschr. 1905, 44a.

Krehl, Erkrankungen des Herzmuskels und die nervösen Herzkrankheiten. Nothnagels spez. Pathol. u. Ther. 1913.

- und Marchand, Handbuch der allgemeinen Pathologie 1913, II, 2.

- Über fettige Degeneration des Herzens. Archiv f. klin. Med. 51, 416.

- Beitrag zur Kenntnis der idiopathischen Herzmuskelerkrankungen. Archiv f. klin. Med. 48, 414.

- Veränderung der Herzmuskulatur bei Klappenfehlern. Kongr. f. inn. Med. 9, 374.

- Zur Pathologie der Herzklappenfehler. Archiv f. klin. Med. 46, 454.

- Pathologische Physiologie 3. 1904.

Külbs, Herzmuskel und Arbeit. Kongr. f. inn. Med. 23, 430.

Lange, Zellkerne des systolischen Herzens. Archiv f. klin. Med. 87, 201.

Lazarus, Klinik der Anämien. Nothnagels spez. Pathol. u. Ther. 1913.

Leube, Spezielle Diagnose innerer Krankheiten 1908.

Letulle, Zit. nach Dehio.

Loyden, Über Fettherz. Zeitschr. f. klin. Med. 5, 1.

- Herzkrankheiten infolge von Überanstrengung. Zeitschr. f. klin. Med. 11, 105.

Lindmann, Archiv f. experim. Pathol. u. Pharmakol. 42, 356.

Mackenzie, Lehrbuch der Herzkrankheiten. Übersetzt von Grote 1910.

Magnan, Le coeur et sa variation en poids chez les mammifères. Ref. Zentralbl. f. inn. Med. 5, 131. 19]3. 
Martius, Ergebnisse der allgemeinen pathologischen Anatomie und Physiologie. Herausgegeben von Lubarsch-Ostertag 1895.

- Über Insuftizienz des Herzmuskels. II. Ref. Kongr. f. inn, Med. 17, 41.

Massini, Über Nitrobenzolvergiftung, Blutbefund und Verhalten des Herzens bei derselben. Archiv f. klin. Med. 101, 72.

Mohr, Zit. nach Kraus.

Morawitz, Blutkrankheiten in Mohr-Stähelins Handbuch 1913.

Moritz, Die allgemeine Pathologie des Herzens in Krehl-Marchand, Handb. d. allgem. Pathol. 2, 2. 1913.

Müller, H., Die progressive perniziöse Anämie. Zürich 1877.

- W., Die Massenverhältnisse des menschlichen Herzens. Hamburg 1883.

- O., und Vöchting, Zur Frage des Herzschlagvolumens. Archiv f. klin. Med. $110,389$.

Myers, Über die Häufigkeit und die Ursachen der Herzkrankheiten bei den Soldaten. Seitz, Monographie.

Nägeli, Blutkrankheiten und Blutdiagnostik 1912.

Radasewsky, Muskelerkrankungen der Vorhöfe des Herzens. Zeitschr. f. klin. Med. 2r, 381.

Romberg, Beiträge zur Herzinnervation. Kongr. f. inn. Med. 9, 356.

- Erkrankungen des Herzmuskels bei Typhus abdomin., Scharlach und Diphtherie. Archiv f. klin. Med. 48, 369; 49, 413.

-- und Hasenfeld, Reservekraft des hypertrophischen Herzens. Archiv f. experim. Pathol. 39. 1897.

- Lehrbuch der Erkrankungen des Herzens und der Blutgefäße 1906.

- und Päßler, Untersuchungen über die allgemeine Pathologie und Therapie der Kreislaufstörung bei akuten Infektionskrankheiten. Archiv f. klin. Med. 64, 652.

Rothberger, Zit. nach Heinz.

Sack, Zit. nach Dehio.

Schmiedeberg, Lehrbuch der Pharmakologie 2. 1906,

v. Schrötter, Die Insuffizienz des Herzmuskels. Kongr. f. inn. Med. I. Ref. 1\%, 23.

Seitz, Die Überanstrengung des Herzens. Berlin 1875.

Stadler, Massenverhältnisse des Kaninchenherzens bei experimentell erzeugter Tricuspidalinsuffizienz. Archiv f. klin. Med. 83, 71.

- Experimentelle und histologische Beiträge zur Herzhypertrophie. Kongr. $\mathbf{f}$. inn. Med. 23, 341.

- Experimentelle und histologische Untersuchungen zur Herzhypertrophie. Archiv f. klin. Med. 91, 98.

Strümpell, Spezielle Pathologie und Therapie 1907.

Tangl, Über die Hypertrophie und das physiologische Wachstum des Herzens. Virchows Archiv 16.

Thurn, Ermüdung des Herzens und die Entstehung von Herzfehlern. Seitz, Monographie.

Tigerstedt, Lehrbuch der Physiologie des Menschen 1905.

Welch, Zit. nach Krehl.

Wideroe, Etude sur l'anatomie pathol, du cœur. Zentralbl. f. inn. Med. 2, 276.

Winkler, Die Herkunft des Fettes bei der Fettmetamorphose des Herzfleisches. Archiv f. experim. Pathol. u. Pharmakol. 48.

Wolfer, Experimentelle Studien zur Reservekraft des hypertrophischen Herzens. Archiv f. experim. Pathol. u. Pharmakol. 68, 435. 